\title{
Structure-based discovery and binding site analysis of histamine receptor ligands
}

\author{
Róbert Kiss, ${ }^{1}$ György M. Keserü ${ }^{2 *}$ \\ ${ }^{1}$ MTA-TTK-NAP B - Drug Discovery Research Group - Neurodegenerative diseases, Institute of \\ Organic Chemistry, Research Centre for Natural Sciences, Hungarian Academy of Sciences, 2 \\ Magyar tudósok körútja, Hungary, Budapest, 1117 \\ ${ }^{2}$ Medicinal Chemistry Research Group, Institute of Organic Chemistry, Research Centre for \\ Natural Sciences, Hungarian Academy of Sciences, 2 Magyar tudósok körútja, Hungary, \\ Budapest, 1117
}

*Corresponding author:

György Miklós Keserü

Phone: +36-1- 382-6821

Email: gyorgy.keseru@ttk.mta.hu

\begin{abstract}
Introduction: Application of structure-based drug discovery in histamine receptor projects was previously hampered by the lack of experimental structures. The publication of the first X-ray structure of the histamine $\mathrm{H} 1$ receptor has been followed by several successful virtual screens and binding site analysis studies of H1-antihistamines. This structure together with several other recently solved aminergic G-protein coupled receptors (GPCRs) enabled the development of more realistic homology models for $\mathrm{H} 2, \mathrm{H} 3$ and $\mathrm{H} 4$ receptors.

Areas covered: In this paper, we review the development of histamine receptors models and their application on drug discovery.

Expert opinion: In our opinion, the application of atomistic histamine receptor models played a significant role in understanding key ligand-receptor interactions as well as in the discovery of novel chemical starting points. The recently solved $\mathrm{H} 1$ receptor structure is a major milestone in structure-based drug discovery, however our analysis also demonstrate that for building $\mathrm{H} 3$ and H4 receptor homology models other GPCRs may be more suitable as a template. For these receptors we envisage that the development of higher quality homology models will significantly contribute to the discovery and optimization of novel $\mathrm{H} 3$ and $\mathrm{H} 4$ ligands.
\end{abstract}

Keywords: histamine, receptor, modelling, structure-based, virtual screening, binding mode 


\section{INTRODUCTION}

Histamine is a well-known signaling molecule and also a neurotransmitter that is recognized by four distinct histamine receptor subtypes numbered by the order of their discovery from $\mathrm{H} 1$ to $\mathrm{H} 4$. Compounds targeting histamine $\mathrm{H} 1$ and $\mathrm{H} 2$ receptors are already on the market as the frontline therapy of allergies and gastric ulcer, respectively. H3 receptors have a role in controlling sleep and cognitive processes that nominates this protein as a drug target against sleep disorders and cognitive dysfunctions. The youngest member of the family is histamine $\mathrm{H} 4$ receptor that has been connected to inflammation and immune responses.

Given the significant pharmacology relevance of histamine receptors a high number of ligands were reported with histaminergic activity. The first H1-antihistamine has been discovered by Ernest Fourneau and Daniel Bovet in 1933 that was recognized by the 1957 Nobel Prize in Medicine. Developing an animal model for anaphylaxis they found that piperoxan inhibited histamine-induced bronchospasm in guinea pigs [1]. After the identification of main pharmacophoric elements, such as the two aromatic rings connected by a carbon or nitrogen atom, the 2-3 atom long spacer to the amine function typically substituted by small alkyl groups, a high number of first generation, non-selective H1-antihistamines were developed. Second generation $\mathrm{H} 1$-antihistamines are more selective compounds with much limited brain penetration that prevents sedative side effects. The design principle for these compounds was also ligandbased. Since most of these compounds are zwitterionic at physiological $\mathrm{pH}$ they could not penetrate across the blood-brain barrier.

The discovery of the $\mathrm{H} 2$ receptor was based on the observation that known $\mathrm{H} 1$-antihistamines had no effect on histamine stimulated secretion of stomach acid. In 1964 drug hunters at Smith, Kline \& French including James Black and Robin Ganellin hypothesized another type of histamine receptors and designed antagonists on the basis of the histamine structure [2]. After synthesizing and testing about 200 compounds they first identified Na-guanylhistamine, a partial $\mathrm{H} 2$-receptor antagonist. Next, ligand-based design helped the team separating functional agonists from antagonists by retaining the imidazole part of the molecule for binding and modifying the sidechain to shift its functional activity. These efforts resulted in a thiourea lead that was converted to similar guanidines to prevent toxic effects. Systematic investigation of guanidine analogues finally led to cimetidine, the first prototypic $\mathrm{H} 2$ antagonist.

While the discovery of H1-antihitamines was basically influenced by a physiological observation the development of $\mathrm{H} 2$ antagonists is one of the first cases of rational drug design. Although the structure of its molecular target was not known the design of new compounds was effectively supported by ligand-based approaches. The first known model of the histamine $\mathrm{H} 1$ receptor was created by Nauta in 1968 proposing the binding mode of 4-methyldiphenhydramine based on the structure-activity relationship and physicochemical properties of H1-antihistamimnes [3] 
The lack of structural information on the receptor proteins prevented the application of structurebased design for new histaminergic ligands. The overall topology of seven transmembrane proteins has been first observed in the purple membrane that provided a $7 \AA$ resolution map of alpha-helical segments by electron cryomicroscopy [4]

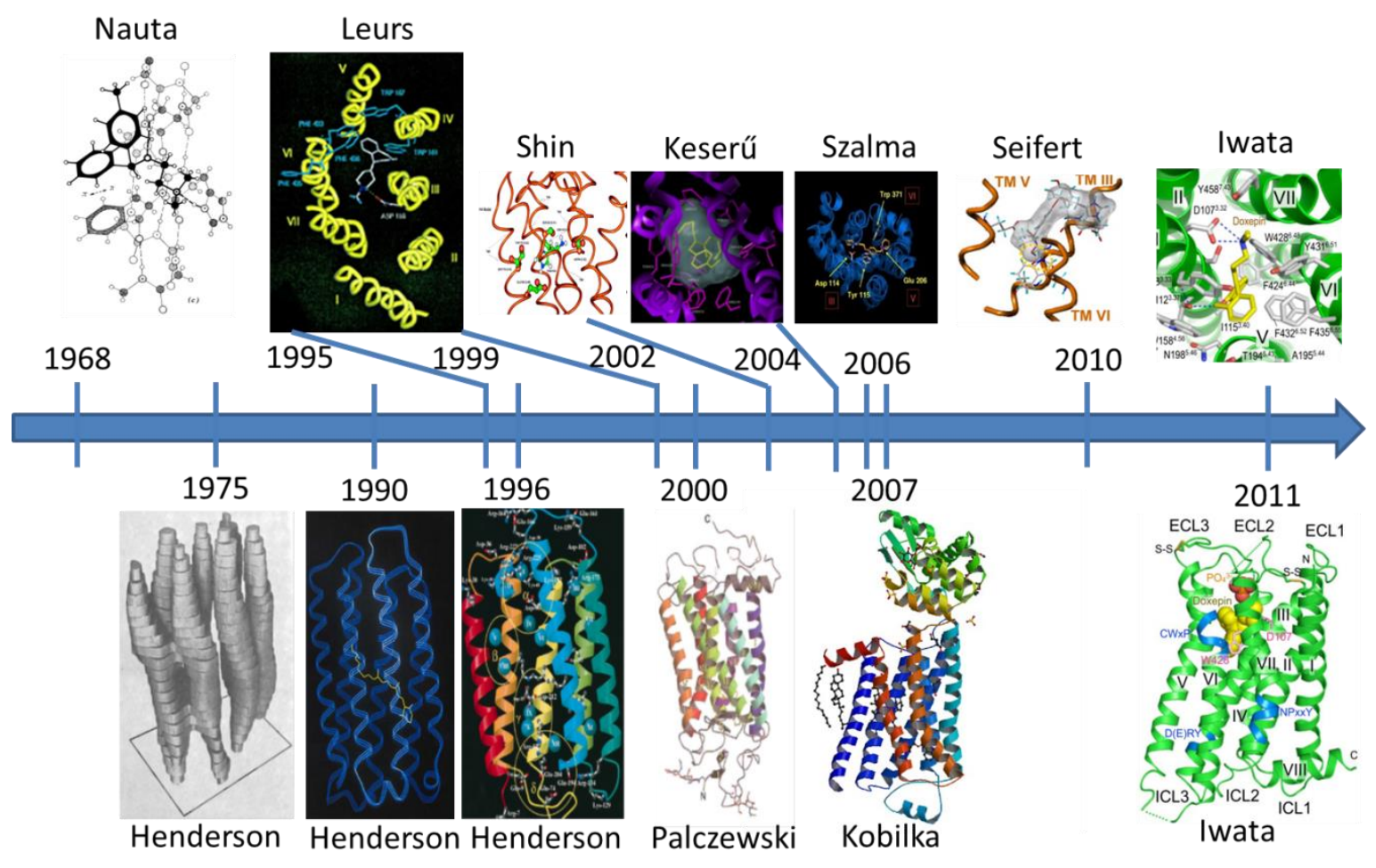

Figure 1. Development in the structural biology of GPCRs (lower panel) and the structure-based design of histaminergic ligands (upper panel)

The first structure in almost atomic resolution has been published by the same group in 1990 for bacteriorhodopsin [5] that was further refined to a $3.5 \AA$ resolution structure in 1996 [6]. Although bacteriorhodopsin is a light-driven proton pump this structure has been used to develop early homology models for GPCRs. Timmermann and Leurs published the first atomistic model of the histamine $\mathrm{H} 1$ receptor in 1995 [7] investigating the binding modes of histamine, 2-methylhistamine and 2-phenyl-histamine as agonists and cyproheptadine as antagonist on bacteriorhodopsin-based homology models. This model has been further refined in a subsequent study analyzing the relationship of the $\mathrm{H} 1$ antagonist pharmacophore model and the binding mode of H1 antagonists in a guinea pig H1R homology model [8]. 
The first true GPCR structure has been published for bovine rhodopsin by the Palczewski group in 2000 [9].Although this structure was a great step ahead for modeling pharmaceutically relevant GPCRs, the largely different function of rhodopsin and also the low sequence identity limited the development of a reliable model of histamine receptors for structure-based design purposes. Despite these limitations improved homology model of the $\mathrm{H} 1$ receptor has been developed and used for the binding mode analysis of different H1-antihistamines [10].

The high resolution rhodopsin structure allowed the construction of homology models for the two new histamine receptors $\mathrm{H} 3$ [11] and H4 [12] as well.

The real breakthrough in the structural biology of aminergic GPCRs was the disclosure of the beta 2 and beta1 structures in 2007 . The availability of these structures allowed the development of better quality homology models especially for the H3 [13] and H4 [14] receptors. Finally, the first X-ray structure of the histamine H1 receptor appeared in 2011 [15] that, together with other high resolution GPCR structures, provided a solid basis for the structure-based design of ligands acting on $\mathrm{H} 1, \mathrm{H} 3$ and $\mathrm{H} 4$ receptors.

In this paper we review the structure based attempts of designing new histaminergic compounds by virtual screening and also understanding their binding mode and optimizing them towards highly active and selective compounds.

\subsection{H1 RECEPTOR}

Timmermann and Leurs published the first atomistic models of the histamine H1 receptor (H1R) in 1995 [7] and 1999 [8]. In these first modeling attempts, the authors proposed binding modes for agonists [7] and antagonists [8] using a homology model of the guinea pig H1R based on the low-resolution bacteriorhodopsin structure. Despite the fact that bacteriorhodopsin is not a GPCR and it lacks some of the conserved GPCR sequence motifs the models provided useful insights. The role of Lys200(5.39 in Ballesteros-Weinstein numbering) in the binding of histamine was suggested by the receptor models and was confirmed by site-directed mutagenesis. Similarly, the authors verified the predicted receptor-antagonist interactions (Trp167(4.56), Phe433(6.52), and Phe436(6.55)) and suggested that they interact with the trans-aromatic ring of the H1 antagonists. Additionally,Lys200(5.39) was predicted to interact with zwitterionic H1 antagonists. The prediction was validated by site-directed mutagenesis: Lys200(5.39)Ala mutation showed 50(acrivastine) to 8-fold (d-cetirizine) loss of affinity while structural analogs lacking the carboxylate group were unaffected. Thus the authors proposed Lys200(5.39) as a specific anchor point for zwitterionic "second generation" H1 antagonists.

An improved homology model of the H1R based on the bovine rhodopsin structure has been developed and used for the binding mode analysis of different H1-antihistamines [10]. In this study, seven new potential aromatic interaction points (Tyr108(3.33), Phe184(5.32), 
Phe190(5.38), Phe199(5.47), Phe424(6.44), Trp428(6.48), Tyr431(6.51)) were suggested that were found in close proximity of the docked antagonists. In addition, it was found that optimal interactions with the endogenous agonist histamine would require the adjustment of transmembrane helix (TM) 5 of the model which was based on the inactive conformation of bovine rhodopsin.

Human and guinea pig H1R models based on the bovine rhodopsin structure were also published [16]. Several known agonists and antagonists were docked and complexes were further refined by MD simulations. The docking predictions suggested that Asn84(2.61) in human H1R which is replaced by a serine in guinea pig H1R can be responsible for the species-selectivity of histaprodifen-histamine dimer, VUF4669 and VUF4801. The authors suggested that Asn84(2.61) is a selectivity switch interacting with Tyr458(7.43) and the latter residue is involved in ligand binding.

The LigPath approach uses a combination of directional guiding (translation of the ligand along a guided line) and Monte-Carlo search (random motions of ligand and receptor) to calculate the ligand's pathway into the binding pocket. LigPath was applied to find the binding path of histaprodifen from the extracellular part into the guinea pig H1R model which was built using the bovine rhodopsin template [17]. The calculations suggested that Tyr194(5.34), Phe193(5.32), Phe436(6.55) and Phe433(6.52) guide the positively charged histaprodifen into the binding pocket.

A bovine rhodopsin based homology model was combined with NMR experiments on histamine to investigate the agonist binding site of H1R [18]. Unfortunately the histamine structure suggested by NMR could not be properly fit into the H1R model. Nevertheless based on the model the authors proposed histamine's amine group to form an ion pair with Asp107(3.32), while the imidazole ring to associate with Asn198(5.46) and Thr194(5.42). They also suggested that the TM8 helix is missing from H1R, however, the presence of this helix was later confirmed by the H1R crystal structure [15].

A guinea-pig H1R model built on the bovine rhodopsin template was used to study the activation mechanism of the receptor by MD simulations [19]. Although only a short simulation time was applied, the restrained simulation resulted in different active and inactive models and thus the authors were able to propose intermediate states and an approximate activation mechanism of the guinea pig H1R. The calculations suggested that a Trp428(6.48)/Phe432(6.52)-switch induces a conformational change in Phe424(6.44) in TM6. An additional difference they found was the interaction of Ser114(3.39) with Asn460(7.45) and Asp73(2.50) in the active and inactive states, respectively.

A H1R homology model based on the $\beta 2$-adrenergic receptor has been reported to investigate the binding mode of AMDA (9-(aminomethyl)-9,10-dihydroanthracene) analogs [20]. Docking 
analysis suggested that AMDA analogs interact with Asp107(3.32) and their rings primarily bind to residues in TM5 and TM6. The role of Tyr108(3.33) and I454(7.39) in binding AMDA analogs was also suggested.

Sato and Hirokawa published an extended template-based modeling approach that they applied to build a H1R model [21]. Their protocol used the bovine rhodopsin and the $\beta 2$-adrenergic receptor structures as templates. The model required some fine-tuning to achieve good enrichment (Tc50 $>0.5$ - an enrichment indicator calculated from a protein ligand interaction fingerprint (PLIF) and its Tanimoto coefficient) in their tests and finally they reached a model with a $1.25 \AA \mathrm{C} \alpha$ RMSD from the H1R X-ray structure.

A $\beta 2$-adrenergic receptor based H1R homology model has also been reported [22]. In this study, ligand affinity of agonist histamine and antagonists mepyramine and (2S, 4R)-(-)-trans-4-phenyl2-N,N-dimethylaminotetralin (PAT) were tested against wild-type and several mutant H1Rs (107Asp(3.32)Ala, Tyr108(3.33)Ala, Trp158(4.56)Ala, Phe199(5.47)Ala, Trp428(6.48)Ala, Tyr431(6.51)Ala, Phe432(6.52)Ala, Phe435(6.55)Ala, Tyr458(7.43)Ala). The results were interpreted using the H1R homology model. In addition, the authors found that in the MD relaxed model Lys191(5.39) was able to move closer to histamine to form tight interactions. The $\beta 2-$ adrenergic receptor based homology model was also compared to the recently published H1R crystal structure and RMSD of $2.91 \AA$ was found.

Finally, the first X-ray structure of H1R in complex with the first generation antihistamine doxepin appeared in 2011 [15]. The structure showed that doxepin directly interacts with several previously suggested binding site residues (Table 1). Furthermore, previously not reported Ile115(3.40) was found to interact with doxepin. Interestingly, an anion-binding region was also identified occupied by a phosphate ion. It is suggested that Lys191(5.39) and/or Lys179(5.27) and/or His450(7.43) are able to interact with carboxylate group containing H1 antagonists validating the predictions based on earlier $\mathrm{H} 1$ models. The previously postulated disulfide bond between Cys180(5.28) in extracellular loop 2 (ECL2) and Cys100(3.25) in TM3 was also confirmed. For seven residues in ECL2 (Phe168-Val174) the authors found no interpretable densities suggesting that some GPCR models lacking parts of ECL2 may still be valid for some purposes as this region is very flexible. The side chain of Asn198(5.46) is pointing toward the membrane bilayer, however, it seemed to be able to easily rotate upon histamine binding. The other histamine binding residue Lys191(5.39) was also found far from either Asp107(3.32) or Asn198(5.46) suggesting that the antagonist conformation shows significant differences from an agonist binding conformation. As proposed in previous modeling studies $[8,10]$ Trp152(4.50) is facing the membrane and does not directly contribute to ligand binding. The 'ionic lock' feature that is found in the rhodopsin but missing from other GPCR structures is also missing from H1R: no interaction between Arg125(3.50) and either Glu410(6.30) or with Asp124(3.49) could be observed. 
One of the first published virtual fragment screening has been performed on the X-ray structure of the human histamine $\mathrm{H} 1$ receptor [23]. A fragment-like subset of ZINC database containing compounds with a formal charge of +1 (108,790 fragments) were docked to the binding pocket of hH1R by PLANTS. Fragments with binding modes contacting to Asp107(3.32) were selected $(95,147)$. Interaction fingerprints were generated from the interactions identified for doxepin cocrystallized with hH1 receptor and used for rank order the remaining database. The novelty of the resulting 354 fragments was checked by comparing them to known $\mathrm{H} 1$ antagonists. Finally, 26 were experimentally tested and 19 fragments showed hH1 affinity (10 $\mu \mathrm{M}$ to $6 \mathrm{nM})$. This $73 \%$ hit rate is remarkable taking that compounds with limited molecular weight and chemically dissimilar to known $\mathrm{H} 1$ ligands were selected for the experimental testing.

In a recent study, the H1R crystal structure was used to analyze the interactions between the H1R and a series of $129 \mathrm{H} 1$ ligands [24]. These authors combined ligand-based CoMSIA analysis with molecular docking into the H1R crystal structure refined with MD. Protonated side chain of the ligands interacted with Asp107(3.32) and interactions were formed with a lipophilic cavity.

Very recently a function-specific virtual screening approach has been reported on the H1R crystal structure [25]. The authors combined energy-based docking scores (PLANTS) with molecular interaction fingerprints (IFP). After screening a fragment-like set of the ZINC database containing compounds with at least one positively charged group, 74 compounds were purchased and tested experimentally. Hit rates of $61 \%, 45 \%$, and $73 \%$, were obtained for the IFP, PLANTS, and combined approaches, respectively.

\subsection{H2 RECEPTOR}

Interestingly, only a small number of structure-based modeling studies have been reported in the literature on H2R. Limited occurrence of such studies, however, could be explained by the successful ligand-based rational drug design strategies that led to the identification of anti-ulcer $\mathrm{H} 2$ inhibitors.

In an early study, a bovine rhodopsin based H2R model was constructed [26]. Asp271(7.36) in the human H2R, which is replaced by Ala in guinea pig H2R, was found to be responsible for species-specificity of guanidine $\mathrm{H} 2$ ligands such as impromidine and arpromidine. The role of Asp271(7.36) was also confirmed by site-directed mutagenesis. The authors suggested that an Asp271(7.36) - Tyr17(1.31) interaction in guinea-pig H2R stabilizes a receptor conformation suitable for accommodating guanidine type ligands. Ionic interaction between the ligands and Asp98(3.32) was observed. Tyr182(5.38) and Asp186(5.42) were suggested as hydrogen bond partners in TM5. 
In a more recent study, a homology model of $H 2 R$ was constructed based on the $\beta 1$-adrenergic receptor [27]. The authors combined a pharmacophore model with structure-based modeling using induced fit docking and MD simulations on selected $\mathrm{H} 2$ agonists. The model was validated for virtual screening in a retrospective study using 47 known $\mathrm{H} 2$ agonists, 38 other subtype selective ligands and 620 assumed inactives. Best performance was found with induced fit docking: rate of retrieved actives increased from $46.8 \%$ to $69.5 \%$ among top $10 \%$ of the ranked database. Regarding binding site residues, the authors found that interactions with Asp98(3.32), Asp186(5.42) and Tyr190(5.46) played key roles in the binding of $\mathrm{H} 2$ agonists.

\subsection{H3 RECEPTOR}

As an early attempt to model the human and rat $\mathrm{H} 3$ receptors a previously developed endothelin receptor model was used as a template to understand species-specificity of ligand binding [28]. In this study, residue differences at positions 119(3.37) and 122(3.40) were suggested and later confirmed experimentally to be responsible for higher affinities of $\mathrm{H} 3$ antagonists in the rat receptor.

After the bovine rhodopsin structure became available, novel homology models were published for H3R. In one study, Axe and coworkers interactively docked known H3 antagonists to a model relaxed by MD simulations in a continuum lipid bilayer model [11]. Dibasic ligands interacted with Asp114(3.32) and Glu206(5.46) simultaneously and formed hydrophobic interactions with aromatic residues Tyr115(3.33) and Trp371(6.48).

In an early study, a bovine rhodopsin based H3R model optimized by short MD simulations in a membrane environment was used for the optimization of $\mathrm{H} 3$ antagonist [29]. A docking-based threshold was defined that was able to discriminate known $\mathrm{H} 3$ ligands with $70 \%$ accuracy.

Another bovine rhodopsin based H3R model was used to rationalize the binding modes of arylbenzofurans [30]. The initial model was built by Swiss-Model server and subsequently short MD simulation in a water-vacuum-water environment was applied. Histamine and selected $\mathrm{H} 3$ antagonists were docked into this model using constraints between (i) Asp114(3.32) and side chain amine moiety and between (ii) imidazole NH and Glu206(5.46). The oxygen of the benzofuran series was found to interact with Tyr189(5.29). Hydrophobic interactions with Ala122(3.40), Phe211(5.51), Val214(5.54), Phe367(6.44), Phe398(7.39), Leu401(7.42), Trp371(6.48) and Tyr189(5.29) were also observed.

In another study, bovine rhodopsin based H3R model built by Gmodel was published [31]. Gmodel is an approach for building GPCR models by normal mode-based refinement that uses a small set of relevant low-frequency vibrational modes derived from the Random Elastic Network model. First, it generates an ensemble of alternative models for docking. Then, the receptor- 
ligand complexes are filtered by mutational and binding affinity data. The binding mode of various ligands including thioperamide, ciproxifan and clobenpropit was analyzed. Imidazole ring and the thiourea groups of thioperamide interacted with Asp114(3.32) and Tyr189(5.29), respectively. Ciproxifan formed interactions with Asp114(3.32), Thr119(3.37), Ala122(3.40), while its ether oxygen was found in close proximity of Tyr374(6.51). Imidazole ring of clobenpropit interacted with Asp114(3.32) while its central NH group was H-bonded to Thr375(6.52) and its benzyl ring was found close to Thr119(3.37) and Ala122(3.40). The model was validated for virtual screening by a large-scale retrospective analysis. One selected model was shown to retrieve $15 \%$ of the actives at the top $1 \%$ of the rank-ordered screening database.

A H3R model using bovine rhodopsin as a template refined in a DPPC membrane by MD simulations was generated and combined with a pharmacophore model to identify novel H3 ligands [32]. The model was retrospectively validated for virtual screening by a set of $418 \mathrm{H} 3$ antagonists with a wide range of affinities $(50 \mu \mathrm{M}-90 \mathrm{pM})$. The discriminating power of the model was assessed by randomly chosen decoys as well as by a focused library resembling a similar physicochemical property distribution as the active set. At the top $80 \%$ of the ranked database $11.4 \%$ and $23 \%$ decoys were found for the randomly selected and focused decoys, respectively. Prospective screening on this model yielded seven virtual hits that were tested in a $\left[{ }^{3} \mathrm{H}\right] \mathrm{N} \alpha$-methylhistamine binding assay. The measured $\mathrm{Ki}$ values ranged between 0.079 and 6.3 $\mu \mathrm{M}$. Based on previous literature data [33] the authors assumed a binding mode for the imidazole containing H3 ligands lacking a protonated amine function, where the imidazole moiety was pointing to Asp114(3.32).

Another bovine rhodopsin based model of H3R was published by Bajda et al. [34]. In their study the binding mode of selected diether derivatives of piperidine and homopiperidine was analyzed. The authors suggested that the heterocyclic nitrogen of the ligands interacts with Glu206(5.46).

Homology model of rat H3R was modeled using the bovine rhodopsin template to analyze the binding mode of imidazole derived H3 antagonists [35]. MD simulations were applied to test the stability of the proposed poses. The authors found that the imidazole ring interacted with Asp114(3.32). Based on the model, 2-[3-(1H-imidazol-4-ylmethyl)-piperidin-1-yl]-1Hbenzimidazole was designed and tested showing high potency (inhibition of $\left[{ }^{3} \mathrm{H}\right] \mathrm{R}-\alpha-$ methylhistamine-specific binding to rat cerebral cortex membranes: $\mathrm{pK}_{\mathrm{i}}=7.81 \pm 0.02$, antagonism of R- $\alpha$-methylhistamine-induced inhibition of twitch response of guinea-pig isolated ileum $\mathrm{pK}_{\mathrm{b}}=8.53 \pm 0.12$ ).

A bovine rhodopsin based model of the H3R was used to investigate the role of TM5 residues in ligand binding [36]. Mutation of Glu206(5.46) showed reduction of affinity and potency of several agonists, such as histamine, R- $\alpha$-methylhistamine, imetit and impentamine. The authors found that the protonated nitrogen of histamine interacts with Asp114(3.32) while the imidazole 
NH group binds to Glu206(5.46). It has to be mentioned that TM5 required some manual adjustments to form interactions with the imidazole ring.

The availability of the $\beta 2$ - and $\beta 1$-adrenergic structures allowed the development of better quality homology models. In particular, a $\beta 2$-adrenergic receptor based H3R model was used to understand the species-differences in pharmacological properties of imoproxifan (inverse agonist at rat H3R, but almost full agonist at human H3R) [13]. The molecular modelling studies suggested that both amino acid differences in TM3, at position 3.37 and 3.40, are responsible for the differences in imoproxifan pharmacology.

Kim et al. published the development of $\mathrm{H} 1, \mathrm{H} 2, \mathrm{H} 3$ and $\mathrm{H} 4$ receptor models using the GEnSeMBLE (GPCR ensemble of structures in membrane bilayer environment) Monte Carlo protocol [37] focusing on the binding mode analysis of subtype selective H3 antagonists [38]. During model building $\sim 35$ million combinations of helix packings were sampled to predict the 10 most stable packings for each of the four subtypes. These 10 best protein structures were used for docking calculations with the DarwinDock Monte Carlo protocol to sample $\sim 50000 \times 10^{20}$ poses for various agonists and antagonists. Glu206(5.46) contributed most to the binding of H3 selective agonists and Glu206(5.46) / Ser203(5.43) were suggested to play a role in $\mathrm{H} 3 / \mathrm{H} 4$ subtype selectivity. In addition, Met378(6.55) in H3R (replaced by a threonine in H4R) was proposed to form subtype specific hydrophobic interactions with the ligands. In the predicted binding mode of histamine, protonated ethylamine and imidazole $\mathrm{NH}$ groups interacted with Asp114(3.32) and Glu206(5.46), respectively. The authors found that human H1R and H3R structures derived from the human $\beta 2$-adrenergic receptor were significantly more favorable energetically than models derived from the turkey $\beta 1$-adrenergic receptor. In contrast, for human $\mathrm{H} 2 \mathrm{R}$ and H4R the structures derived from the turkey $\beta 1$-adrenergic receptor were most favorable.

Sirci and coworkers reported the identification of new H3 antagonist fragments using ligandbased and protein-based molecular fingerprints [39]. In their study they used the FLAP approach (FLAP: Fingerprint for Ligands And Protein) with interacting molecular fields (MIFs) to identify pharmacophores on a H3R homology model built on the H1R structure as a template. Linear discrimination analysis (LDA) was used to discriminate compounds by their affinities. In a retrospective study FLAP outperformed both Tanimoto ECFP-4 similarity, ROCS shape similarity and also docking methods including PLANTS and GOLD. Subsequently, the authors screened 156,090 fragment-like compounds from ZINC using FLAP. Twenty nine compounds were selected and tested experimentally. Nineteen compounds (63\%) with significant $\mathrm{H} 3$ affinity (0.5-10 $\mu \mathrm{M})$ were identified.

Levoin and coworkers analyzed the binding mode of dibasic H3 ligands using a H1R based H3R model [40]. They proposed a ligand orientation perpendicular to the membrane plane, bridging Glu206(5.46) to acidic amino acids of the extracellular loops, such as Glu175(4.51) and Glu191(5.31). Interestingly, the authors found that this binding mode was more in line with 
ligand-based alignment of dibasic H3 ligands than other models involving Asp114(3.32). It has to be mentioned that the proposed binding modes have not been confirmed experimentally yet.

Very recently, a series of 20 new chlorophenoxyalkylamine derivatives was synthesized and tested against human H3R [41]. The binding modes of these compounds were predicted on a H3R model based on the recently published M3 muscarinic acetylcholine receptor due to its highest sequence homology to H3R. The authors observed salt bridge between the nitrogen of most cycloalkylamine ligands and Glu206(5.46). Further interactions were seen with residues Tyr189(5.29), Trp174(4.50), Leu177(4.53), Ala190(5.30), Glu191(5.31), Tyr194(5.34), $\operatorname{Trp196(5.36).}$

\subsection{H4 RECEPTOR}

After the discovery of the $\mathrm{H} 4$ receptor, one of the earliest modeling studies was published by Shin et al. [12]. In this paper, a homology model of human H4R was constructed based on the bovine rhodopsin structure. The authors assumed that the protonated side chain amine and NH groups of histamine interact with Asp94(3.32) and Glu182(5.46), respectively. Their role in histamine binding was confirmed by site-directed mutagenesis. Potential role of Asn147(4.57) and Ser320(6.52) in receptor activation was also suggested by the experiments.

Our group reported H4R homology models based on the bovine thodopsin template [42]. The binding mode of histamine was predicted by analyzing lipophilic and H-bonding surfaces of the binding site and the results of docking calculations. We suggested that the protonated amine function of histamine interacts with Glu182(5.46), while the imidazole ring forms H-bonds with Asp94(3.32) and Thr323(6.55). The role of the latter residue in histamine binding has not been investigated experimentally yet. In this study ligand supported homology models with histamine, JNJ7777120 and OUP-16 were constructed using docking and subsequent optimization. The discriminating power of the models was tested in a retrospective screening scenario. Highest enrichments factors ranging 61-92 were obtained with a ligand supported model using histamine as a ligand.

In a subsequent study, we used our previously developed histamine-H4R and JNJ7777120-H4R complexes to investigate the activation mechanism of H4R [43]. The complexes were subjected to MD simulations. During the simulations, the interaction between histamine's imidazole NH and Asp94(3.32) broke, however, both residues formed strong interactions with Glu165(5.29) resulting in a stable triad. Interestingly, histamine formed an interaction with Asn147(4.57) that was previously proved to be important in hH4R activation [12]. When simulating the histamineH4R complex, we found several signs of GPCR activation including the intracellular part of TM6 moved outward relative to TM3 and TM7. The interaction with Glu182(5.46) in the JNJ7777120- 
H4R complex remained stable, while the interaction of the indole $\mathrm{NH}$ and Asp94(3.32) broke for a short period of time and re-formed.

Our group published a large-scale virtual screening study using a bovine rhodopsin based hH4R model [44]. In this study, $>8.7 \mathrm{M}$ compounds were screened by docking and the most promising hits were selected by two protocols: (i) docking poses for the highest ranked 2,000 structures were inspected visually and (ii) the highest ranked 45,000 ligands were post-filtered for compounds with at least one protonated amine and one additional H-bond donor moieties and subjected to diversity selection using MACCS Structural Keys with a maximum Tanimoto coefficient of 0.7 . The hit rates were $4.6 \%$ and $7.2 \%$ for selection methods (i) and (ii), respectively, suggesting that a combined structure- and ligand-based approach can be more effective than standalone docking. Altogether 16 compounds showed significant $\mathrm{H} 4$ affinity (minimum $20 \%\left[{ }^{3} \mathrm{H}\right]$ histamine displacement at $5 \mu \mathrm{M}$ concentration) including a compound with a $\mathrm{K}_{\mathrm{i}}$ of $85 \mathrm{nM}$. Several novel scaffolds were identified that could serve as starting points for subsequent medicinal chemistry optimizations.

Our group also reported a retrospective and prospective screening study using snapshots from a previously described MD simulation of H4R built on the bovine rhodopsin structure [45]. Ensemble docking on selected snapshots that demonstrated highest enrichment factors in the retrospective analysis was used to identify new H4 ligands.

Based on the bovine rhodopsin template, Jongejan et al. constructed a homology model of H4R and used it to interpret site-directed mutagenesis data for $\mathrm{H} 4$ agonists including histamine, clozapine and nonimidazole agonist VUF 8430 [46]. Interestingly the authors found that the binding of histamine and VUF8430 are significantly affected by the Glu182(5.46)Gln mutation, while the effect on clozapine and JNJ7777120 binding was minor. The authors suggested that the protonated amine functionality of the ligands interacts with Asp94(3.32). Interestingly they also suggested that the vicinity of ionic Asp94(3.32) changes the $\mathrm{pK}_{\mathrm{a}}$ of Glu182(5.46) and thus the latter residue is assumed to be protonated by default. Another plausible interpretation of the mutational results is that clozapine and JNJ7777120 only require an H-bond acceptor functionality at position 182(5.46) and the ionic carboxylate group is not necessary for binding. It is also possible that while some ligands are able to interact with the side chain oxygen of Gln182(5.46), others such as histamine and VUF8430 may only be able to reach the terminal amine group of Gln182(5.46) which replaces the oxygen of Glu182(5.46). Nevertheless, further studies would be necessary to draw firm conclusions regarding the binding mode of these ligands at the H4R binding site.

After the adrenergic GPCR crystal structures became available, several novel H4R models utilizing these templates have been published. In a study of Schultes et al. the binding mode of substituted and unsubstituted indolecarboxamides and 2-aminopyrimidines were reported [47]. They built separate H4R homology models using H1R or the $\beta 2$-adrenergic structures. In the 
models residues Asp94(3.32) and Glu182(5.46) were considered in their deprotonated form. It was found that both indolecarboxamides and 2-aminopyrimidines formed more stable interaction with these residues when the piperazine group faced the Asp94(3.32) residue. Additionally, Leu175(5.39) formed interaction with most ligands in the above binding mode. Leu175(5.39)Val mutation reduced the affinity of all tested ligands by $0.6-1.5 \mathrm{pK}_{\mathrm{a}}$ units.

While looking for amino acids involved in the binding of $\mathrm{H} 4$ agonists, Lim et al. identified Phe169 in ECL2 to be responsible for species differences in agonist affinity between the human and mouse H4Rs [14].

Igel and coworkers reported the synthesis of cyanoguanidine-type $\mathrm{H} 4$ agonists [48]. The most potent compound (2-cyano-1-[4-(1H-imidazol-4-yl)butyl]-3-[(2-phenylthio)ethyl]guanidine (URPI376)) (hH4R $\mathrm{pEC}_{50}=7.47(\alpha=0.93)$ ) showed only negligible effects on H1R or H2R and significant selectivity over $\mathrm{H} 3 \mathrm{R}\left(\mathrm{hH} 3 \mathrm{R} \mathrm{pK}_{\mathrm{B}}=6.00(\alpha=-0.28)\right)$. Its binding mode was analyzed using a hH4R homology model based on the $\beta 2$-adrenergic receptor after manual docking in a previously suggested binding mode [46] assuming a protonated Glu182(5.46) and refined by MD simulations. The predicted binding mode suggested that the cyanoguanidine moiety forms hydrogen bonds with Asp94(3.32) as well as the hH4R-specific Arg341(7.36) residue.

More recently the binding mode of $\mathrm{H} 1$ agonists and antagonists at the H4R binding site were analyzed to identify dual H1/H4 acting ligands [49]. Eighteen $\mathrm{H} 1$ antagonists and $22 \mathrm{H} 1$ agonists showed lower affinity to hH4R than to hH1R. Suprahistaprodifen the only tested ligand that acted as a partial agonist on hH4R was docked into inactive and active hH4R models in two different orientations. The inactive hH4R was built using the crystal structure of the human $\beta 2$-adrenergic receptor, while the active model of the hH4R was generated with distance-restrained MD simulation. The authors suggest that astemizole possessing some similarity with JNJ7777120 could be a good starting point for the development of dual $\mathrm{H} 1 / \mathrm{H} 4$ antagonists.

The same model was used for the binding mode analysis of phenylhistamine, histaprodifen and phenoprodifen analogs [50]. For the development of an active-state model the authors used the opsin crystal structure. The positively charged amine of phenylhistamines was found to interact with Asp94(3.32), while the imidazole and phenyl groups were accommodated by an aromatic pocket consisting of Tyr95(3.33), Trp316(6.48) and Tyr319(6.51). The imidazole group did not form stable H-bonds during the MD simulations. Similar binding mode was detected for histaprodifen. The authors also predicted Gibbs energies of ligand binding with GROMACS 4.0.2 using thermodynamic integration that yielded a good correlation with the experimentally determined affinities $\left(r^{2}=0.89\right)$.

3D-QSAR models were also combined with receptor docking to identify critical ligand binding residues in H4R [51]. H4R was modeled using the $\beta 2$-adrenergic receptor as a template refined 
by MD simulations. The authors suggest that there are two potential binding modes for clobenpropit, while the addition of a cyclohexyl group to the isothiourea moiety prevents one of them. They found that while the binding of clobenpropit is affected by mutations of Gln347(7.42) or Thr323(6.55) the cyclohexyl analog is only significantly affected by mutated residue Asn147(4.57). They suggest that introducing a larger residue in the 4.57 position may stabilize the orientation of Glu182(5.46) in a way that is not compatible with the binding mode of the cyclohexyl analog.

A new H4R model was created using the structure of the $\beta 2$-adrenergic receptor selected by the ITASSER approach [52]. A total of 392 structural analogs of JNJ7777120, thioperamide and VUF6002 retrieved from PubChem were docked into the model and six compounds with particularly high docking scores were identified. Their binding mode shared an interaction with the conserved Asp94(3.32) residue.

A chimeric H4R model has been created using the H1R crystal structure while the kink in helix TM4 was modeled based on the human $\beta 2$-adrenergic receptor. [53]. JNJ7777120 was first manually docked into the receptor, and after minimization JNJ7777120 was re-docked by IFD and the complex was subjected to MD simulations. Structurally diverse frames were selected for fragment docking based on RMSD values of the interacting residues around the JNJ7777120 ligand. Virtual screening of 13,000 fragments gave 11 and 8 hits with larger than $20 \%$ displacement at $10 \mu \mathrm{M}$ on a single structure or on an ensemble of structures, respectively. The identified hits formed interactions with Asp94(3.32) and/or Glu182(5.46).

In a retrospective study, preliminary H4R homology models were prepared as described above [53] and the impact of molecular dynamics sampling on the discriminative power of structurebased virtual screening was analyzed [54]. The study utilized the GDD ligand set [55] and revealed that particular snapshots from MD were able to outperform the initial models (enrichment factors were 26.7 and 13.3, respectively).

Pappalardo et al. published a successful application of ligand- and structure-based modeling approach to index chemicals for their $\mathrm{H} 4$ antagonism [56]. In their study, ligand-based Intelligent Learning Engine (ILE) and Iterative Stochastic Elimination (ISE) approaches were combined with molecular docking into H4R models based on the H1R crystal structure as a template complemented with MD refinement in a DOPC membrane model. The combined approach showed enrichment factors of 14.6-16.4 on a ChEMBL validation set. Subsequently, the authors made a selection from the ZINC database, and the approach resulted in 11 candidate ligands awaiting for experimental validation.

Feng et al. published a study using H1R based H4R models refined by MD [57]. They docked several H4 antagonists and agonists into preliminary models of H4R and H3R. It was found that most docked ligands primarily interact with Asp94(3.32) and Glu182(5.46) through their 
protonated ethylamine side chains and imidazole NH groups, respectively. MD simulations of clobenpropit showed that in both possible binding modes the interaction formed by the protonated amine and either Asp94(3.32) or Glu182(5.46) was more stable, while the imidazole interaction was unstable. The authors also report that the simulations in H4R indicated subtype specific interactions with Glu155(5.19) and Thr323(6.55), however it has to be noted that clobenpropit has a similar (slightly lower) affinity for $\mathrm{H} 4 \mathrm{R}$ vs $\mathrm{H} 3 \mathrm{R}\left(\mathrm{H} 3 \mathrm{R}\right.$ : $\mathrm{pK} \mathrm{i}_{\mathrm{i}}=8.6 \mathrm{H} 4 \mathrm{R}$ : $\mathrm{pK}_{\mathrm{i}}=8.1$ ), therefore their effect on clobenpropit binding may be less significant. Simulations in the presence of histamine showed conformational changes in TM5, TM6 and TM7. An outward movement of the intracellular end of TM6 could be also observed which is consistent with a proposed activated form of GPCRs [58].

In another study, the binding mode of 2-amino-4-(4-methylpiperazin-1-yl)-1,3,5-triazine derivatives with different aryl substituents in the 6-position was investigated at the H4R binding site [59]. The authors used a H1R based homology model of H4R following the protocol of Feng et al. [57]. For all docked ligands, interactions with only Asp94(3.32) were found. On the other hand, the protonated methylpiperazine nitrogen in most active ligands was found in very close proximity to Glu182(5.46) and could form weak hydrogen bonds. Hydrophobic interactions were found with the following residues: Tyr225(6.51), Tyr95(3.33), Phe228(6.54), Thr178(5.42), Val64(2.53), Ile69(2.58) and Trp90(3.28).

Homology model of H4R based on the H1R crystal structure has been also used for the structurebased optimization of a set of bispyrimidines [60]. In this work, the authors attempted to exchange the metabolic hot spot methylpiperazine moiety that is frequently found in both the indolecarboxamide and 2-aminopyrimidine series of $\mathrm{H} 4$ ligands. The methylpiperazine was replaced by another 2-aminopyrimidine group yielding bispyrimidines with improved metabolic stability. Interestingly, indolecarboxamides and 2-aminopyrimidines were similarly affected by the Leu175(5.39)Val mutation. When the aromatic indole / benzene rings were substituted with a chlorine the mutation caused a drop in affinity, while unsubstituted compounds were unaffected. This very interesting finding suggests that the corresponding rings occupy a similar pocket in H4R and the substitution position is close to Leu175(5.39).

\section{CONCLUSION}

The physiological and pathophysiological significance of histamine receptors initiated a high number of research programs aiming subtype selective histamine receptor ligands. In addition to ligand based approaches that typically drove the discovery of selective histamine $\mathrm{H} 2$ receptor antagonist structure based approaches are contributed significantly to the identification of several histamine $\mathrm{H} 1$ and more importantly a number of histamine $\mathrm{H} 3$ and $\mathrm{H} 4$ ligands. In the lack of high resolution structure for histamine receptors structure based approaches used primarily homology models. A variety of virtual screening protocols have been developed that allowed the identification of novel subtype selective chemotypes for $\mathrm{H} 1, \mathrm{H} 3$ and $\mathrm{H} 4$ receptors. Docking based binding mode analyses often coupled to site directed mutagenesis studies were successfully used 
understanding protein-ligand interactions and developing structure-activity relationships (SAR). The increasing availability of GPCR X-ray structures provides further templates for the development of higher quality homology models that, in combination with further histamine receptor structures would make the contribution of structure based approaches even more significant.

\section{EXPERT OPINION}

The early days of histamine research were impacted by ligand-based design that resulted in a number of histamine $\mathrm{H} 1$ and $\mathrm{H} 2$ receptor ligands both of which have significant contribution to human pharmacotherapy. The endogenous agonist, histamine was used as a starting point designing $\mathrm{H} 1$ and $\mathrm{H} 2$ receptor antagonists. The increased availability of GPCR structures, however, also contributed to the understanding of receptor functions, activation mechanism and the molecular mechanism of drug actions. Characterization of the $\mathrm{H} 1$ and in less extent the $\mathrm{H} 2$ binding site was typically realized by binding mode analyses often connected to site-directed mutagenesis studies. These combined analyses led to the identification of key residues with significant role in subtype and species selectivities as well as functional activities. Evolution of structural templates from the low resolution electron cryo-microscopy structure of bacteriorhodopsin, through rhodopsin and $\beta$-adrenergic receptors to the first high resolution structure of the human $\mathrm{H} 1$ receptor allowed the development of several histamine receptor models with improved quality. The increasing knowledge on the structural details of protein ligand interactions was especially important for histamine $\mathrm{H} 3$ and $\mathrm{H} 4$ receptor ligands. Since the structural biology of GPCRs developed parallel with the discovery of these receptors structural studies on $\mathrm{H} 3$ and $\mathrm{H} 4$ receptors contributed significantly to the design of highly potent and selective ligands. The phylogenetic and sequential differences between $\mathrm{H} 1, \mathrm{H} 2$, and H3, H4 receptors suggest the latter two histamine receptors more similar to each other than $\mathrm{H} 1$ or $\mathrm{H} 2$ receptors. Consequently, the design of selective $\mathrm{H} 3$ and $\mathrm{H} 4$ compounds can benefit heavily from structural models of these receptors and the binding mode analysis of their ligands. A high number of studies contributed to the structural description and comparative analysis of $\mathrm{H} 3$ and H4 binding sites that allowed the identification of selective high affinity ligands of both targets. The improved quality of the homology models also allowed a number of virtual screening studies that resulted in new chemotypes for $\mathrm{H} 3$ and $\mathrm{H} 4$ ligand discovery. Given the increasing number of GPCR structures one of the key questions of homology modeling is the selection of appropriate templates. Although the crystal structure of the $\mathrm{H} 1$ receptor has already been solved it seems that this structure is less than optimal for $\mathrm{H} 3$ and $\mathrm{H} 4$ structural models. Analysis of receptor sequences and also the results of binding mode analyses and virtual screening studies suggest that $\beta$-adrenergic and muscarinic structures might serve as better templates [61]. From the present set of potential templates muscarinic M1, M2 and M3 structures seem to be preferred (Table 5), however, this should be carefully considered before developing new models of H3 and H4 receptors. The other crucial point in model development is the refinement procedure. Recent studies revealed that induced fit docking of known ligands together with site-directed 
mutagenesis studies could improve the models significantly. Similar benefits could be realized with ligand supported homology modeling protocols. The refinement of homology models is often completed with molecular dynamics simulations that might improve the quality of the binding site. Retrospective virtual screening can be used evaluating the resulted structural models selecting the best quality structure with the highest enrichment. Alternatively, multiple frames from molecular dynamics simulations would also serve as receptor structures for ensemble docking applications that can maximize the outcome of prospective virtual screening. Structurebased design of new histamine $\mathrm{H} 3$ and $\mathrm{H} 4$ ligands, however, requires intensive interactions between computational and experimental scientists. Computational experts together with medicinal chemists and molecular and structural biologists can contribute more effectively to the design of new chemotypes for histaminergic receptors, especially for the therapeutically less exhausted $\mathrm{H} 3$ and $\mathrm{H} 4$ receptors. We expect that the next significant step forward in the field should be the disclosure of high resolution X-ray structures of these pharmacologically highly relevant drug targets.

Funding details. This work was supported by the Hungarian Brain Research Program under Grant KTIA NAP 13-2014-0009.

\section{Article highlights box:}

- Before 2011 homology models dominated the structure-based drug design of histamine receptor ligands

- Studies on the binding mode analysis of histamine receptor ligands combined with site-directed mutagenesis successfully identified key receptor interaction points

- Virtual screening studies complemented with experimental testing yielded numerous chemical starting points for optimization

- The publication of the $\mathrm{H} 1$ receptor in complex with doxepin was a major milestone in the field

- Modelling of the pharmaceutically highly relevant $\mathrm{H} 3$ and $\mathrm{H} 4$ receptors, that are phylogenetically more distinct from H1R, is still challenging

\section{REFERENCES}


1. Fourneau E, Bovet D. Recherches sur l'action sympathicolytique d'un nouveau dérivé du dioxane. Archives Internationales de Pharmacodynamie et de Thérapie, 1933;46:178-191.

2. Molinder HK. The development of cimetidine: 1964-1976. A human story. J Clin Gastroenterol. 1994;19:248-254.

3. Nauta WT, Harms AF. Proceedings of the international pharmacol. meeting, 3rd edn, vol 7. Pergamon Press, Oxford, p 305. 1968.

4. Henderson R, Unwin PN. Three-dimensional model of purple membrane obtained by electron microscopy. Nature. 1975;257:28-32.

5. Henderson R, Baldwin JM, Ceska TA, et al. Model for the structure of bacteriorhodopsin based on high-resolution electron cryo-microscopy. J Mol Biol. 1990;213:899-929.

6. Grigorieff N, Ceska TA, Downing KH, et al. Electron-crystallographic refinement of the structure of bacteriorhodopsin. J Mol Biol. 1996;259:393-421.

7. ter Laak AM, Timmerman H, Leurs R, et al. Modelling and mutation studies on the histamine H1-receptor agonist binding site reveal different binding modes for H1-agonists: Asp116 (TM3) has a constitutive role in receptor stimulation. J Comput Aided Mol Des. 1995;9:319-330.

8. Wieland K, ter Laak AM, Smit MJ, et al. Mutational analysis of the antagonist-binding site of the histamine H(1) receptor. J Biol Chem. 1999;274:29994-30000.

9. Palczewski K, Kumasaka T, Hori T, et al. Crystal structure of rhodopsin: A G protein-coupled receptor. Science. 2000;289:739-745.

10. Kiss R, Kovári Z, Keseru GM. Homology modelling and binding site mapping of the human histamine H1 receptor. Eur J Med Chem. 2004;39:959-967.

11. Axe FU, Bembenek SD, Szalma S. Three-dimensional models of histamine H3 receptor antagonist complexes and their pharmacophore. J Mol Graph Model. 2006;24:456-464.

12. Shin N, Coates E, Murgolo NJ, et al. Molecular modeling and site-specific mutagenesis of the histamine-binding site of the histamine H4 receptor. Mol Pharmacol. 2002;62:38-47.

13. Schnell D, Strasser A, Seifert R. Comparison of the pharmacological properties of human and rat histamine H(3)-receptors. Biochem Pharmacol. 2010;80:1437-1449.

14. Lim HD, Jongejan A, Bakker RA,et al. Phenylalanine 169 in the second extracellular loop of the human histamine $\mathrm{H} 4$ receptor is responsible for the difference in agonist binding between human and mouse H4 receptors. J Pharmacol Exp Ther. 2008;327:88-96.

15. Shimamura T, Shiroishi M, Weyand S, et al. Structure of the human histamine H1 receptor complex with doxepin. Nature. 2011;475:65-70. 
**This paper reports the first high resolution X-ray structure of the human histamine $\mathrm{H} 1$ receptor 16. Bruysters M, Jongejan A, Gillard M, et al. Pharmacological differences between human and guinea pig histamine H1 receptors: Asn84 (2.61) as key residue within an additional binding pocket in the H1 receptor. Mol Pharmacol. 2005;67:1045-1052.

17. Strasser A, Wittmann HJ. LigPath: a module for predictive calculation of a ligand's pathway into a receptor-application to the gpH1-receptor. J Mol Model. 2007;13:209-218.

18. Prasad Ratnala VR, Hulsbbergen FB, de Groot HJ, et al. Analysis of histamine and modeling of ligand-receptor interactions in the histamine H(1) receptor for Magic Angle Spinning NMR studies. Inflamm Res. 2003;52:417-423.

19. Strasser A, Wittmann HJ. Analysis of the activation mechanism of the guinea-pig Histamine H1-receptor. J Comput Aided Mol Des. 2007;21:499-509.

20. Shah JR, Mosier PD, Roth BL, et al. Synthesis, structure-affinity relationships, and modeling of AMDA analogs at 5-HT2A and H1 receptors: structural factors contributing to selectivity. Bioorg Med Chem. 2009;17:6496-6504.

21. Sato M, Hirokawa T. Extended template-based modeling and evaluation method using consensus of binding mode of GPCRs for virtual screening. J Chem Inf Model. 2014;54:31533161.

22. Cordova-Sintjago TC, Fang L, Bruysters M, et al. Molecular determinants of ligand binding at the human histamine H1 receptor: Site-directed mutagenesis results analyzed with ligand docking and molecular dynamics studies at $\mathrm{H} 1$ homology and crystal structure models. J Chem Pharm Res. 2012;4:2937-2951.

23. de Graaf C, Kooistra, AJ, Vischer et al. Crystal structure-based virtual screening for fragment-like ligands of the human histamine H1 receptor. J Med Chem. 2011;54:8195-8206.

**This study reports the first virtual screening study against the X-ray structure of the human histamine $\mathrm{H} 1$ receptor

24. Yang Y, Li Y, Pan Y, et al. Computational Analysis of Structure-Based Interactions for Novel $\mathrm{H}_{1}$-Antihistamines. Int J Mol Sci. 2016;17.pii:E129.

25. Kooistra AJ, Vischer HF, McNaught-Flores D, et al. Function-specific virtual screening for GPCR ligands using a combined scoring method. Sci Rep. 2016;6:28288.

*This is the first virtual screen identified function-specific histamine $\mathrm{H} 1$ receptor antagonists/inverse agonists 
26. Kelley MT, Bürckstümmer T, Wenzel-Seifert K, et al. Distinct interaction of human and guinea pig histamine H2-receptor with guanidine-type agonists. Mol Pharmacol. 2001;60:12101225.

27. Sun X, Li Y, Li W, et al. Computational investigation of interactions between human $\mathrm{H} 2$ receptor and its agonists. J Mol Graph Model. 2011;29:693-701.

28. Yao BB, Hutchins CW, Carr TL, et al. Molecular modeling and pharmacological analysis of species-related histamine H(3) receptor heterogeneity. Neuropharmacology. 2003;44:773-786.

29. Levoin N, Calmels T, Poupardin-Olivier O, et al. Refined docking as a valuable tool for lead optimization: application to histamine $\mathrm{H} 3$ receptor antagonists. Arch Pharm (Weinheim). 2008;341:610-623.

30. Dastmalchi S, Hamzeh-Mivehroud M, Ghafourian T, et al. Molecular modeling of histamine H3 receptor and QSAR studies on arylbenzofuran derived H3 antagonists. J Mol Graph Model. 2008;26:834-844.

31. Rai BK, Tawa GJ, Katz AH, et al. Modeling G protein-coupled receptors for structure-based drug discovery using low-frequency normal modes for refinement of homology models: application to H3 antagonists. Proteins. 2010;78:457-473.

32. Schlegel B, Laggner C, Meier R, et al. Generation of a homology model of the human histamine $\mathrm{H}(3)$ receptor for ligand docking and pharmacophore-based screening. J Comput Aided Mol Des. 2007;21:437-453.

33. Jacobsen ML, Rimvall K, Hastrup S, et al. XXXII Annual Meeting of the European Histamine Research Society; 2003; Noordwijkerhout, Netherlands.

34. Bajda M, Kuder KJ, Lażewska D, et al. Dual-acting diether derivatives of piperidine and homopiperidine with histamine $\mathrm{H}(3)$ receptor antagonistic and anticholinesterase activity. Arch Pharm (Weinheim). 2012;345:591-597.

35. Lorenzi S, Mor M, Bordi F, et al. Validation of a histamine $\mathrm{H} 3$ receptor model through structure-activity relationships for classical H3 antagonists. Bioorg Med Chem. 2005;13:56475657.

36. Uveges AJ, Kowal D, Zhang Y, et al. The role of transmembrane helix 5 in agonist binding to the human H3 receptor. J Pharmacol Exp Ther. 2002;301:451-458.

37. Abrol R, Bray JK, Goddard WA 3rd. Bihelix: Towards de novo structure prediction of an ensemble of G-protein coupled receptor conformations. Proteins. 2012;80:505-518. 
38. Kim SK, Fristrup P, Abrol R, et al. Structure-based prediction of subtype selectivity of histamine H3 receptor selective antagonists in clinical trials. J Chem Inf Model. 2011;51:32623274.

*This study reports homology models for all human histamine receptor subtypes and that are useful for the structure-based selection of subtype selectivity

39. Sirci F, Istyastono EP, Vischer HF et al. Virtual fragment screening: discovery of histamine H3 receptor ligands using ligand-based and protein-based molecular fingerprints. J Chem Inf Model 2012;52:3308-3324.

40. Levoin N, Labeeuw O, Krief S, et al. Determination of the binding mode and interacting amino-acids for dibasic H3 receptor antagonists. Bioorg Med Chem. 2013;21:4526-4529.

41. Kuder K, Łażewska D1, Latacz G, et al. Chlorophenoxy aminoalkyl derivatives as histamine H(3)R ligands and antiseizure agents. Bioorg Med Chem. 2016;24:53-72.

42. Kiss R, Noszál B, Rácz A, et al. Binding mode analysis and enrichment studies on homology models of the human histamine H4 receptor. Eur J Med Chem. 2008;43:1059-1070.

43. Jójárt B, Kiss R, Viskolcz B, et al. Activation mechanism of the human histamine $\mathrm{H} 4$ receptor--an explicit membrane molecular dynamics simulation study. J Chem Inf Model. 2008;48:1199-1210.

44. Kiss R, Kiss B, Könczöl Á et al. Discovery of novel human histamine H4 receptor ligands by large-scale structure-based virtual screening J Med Chem 2008;51:3145-3153.

* This is the largest scale structure-based virtual screen led to a number of novel human histamine $\mathrm{H} 4$ receptor chemotypes

45. Kiss R, Jójárt B, Schmidt É, et al. Identification of Novel Histamine H4 Ligands by Virtual Screening on Molecular Dynamics Ensembles. Molecular Informatics. 2014;33:264-268.

46. Jongejan A, Lim HD, Smits RA, et al. Delineation of agonist binding to the human histamine $\mathrm{H} 4$ receptor using mutational analysis, homology modeling, and ab initio calculations. J Chem Inf Model. 2008;48:1455-463.

47. Schultes A, Nijmeijer S, Engelhardt H, et al. Mapping histamine H4 receptor-ligand binding modes. Med. Chem. Commun. 2013;4:193-204.

48. Igel P, Geyer R, Strasser A, et al. Synthesis and structure-activity relationships of cyanoguanidine-type and structurally related histamine H4 receptor agonists. J Med Chem. 2009;52:6297-6313. 
49. Deml KF, Beermann S, Neumann D, et al. Interactions of histamine H1-receptor agonists and antagonists with the human histamine H4-receptor. Mol Pharmacol. 2009;76:1019-1030.

50. Wittmann HJ, Elz S, Seifert R, et al. N ( $\alpha$ )-Methylated phenylhistamines exhibit affinity to the hH(4)R-a pharmacological and molecular modelling study. Naunyn Schmiedebergs Arch Pharmacol. 2011;384:287-299.

51. Istyastono EP, Nijmeijer S, Lim HD, et al. Molecular determinants of ligand binding modes in the histamine $\mathrm{H}(4)$ receptor: linking ligand-based three-dimensional quantitative structureactivity relationship (3D-QSAR) models to in silico guided receptor mutagenesis studies. J Med Chem. 2011;54:8136-8147.

52. Christopher F, Thangam EB, Suresh MX. A bioinformatics search for selective histamine h4 receptor antagonists through structure-based virtual screening strategies. Chem Biol Drug Des. 2012;79:749-759.

53. Vass M, Schmidt É, Horti F, et al. Virtual fragment screening on GPCRs: a case study on dopamine D3 and histamine H4 receptors. Eur J Med Chem. 2014;77:38-46.

54. Tarcsay A, Paragi G, Vass M, et al. The impact of molecular dynamics sampling on the performance of virtual screening against GPCRs. J Chem Inf Model. 2013;53:2990-2999.

55. Gatica EA, Cavasotto CN. Ligand and Decoy Sets for Docking to G Protein-Coupled Receptors. J. Chem Inf. Model. 2012;52:1-6.

56. Pappalardo M, Shachaf N, Basile L, et al. Sequential application of ligand and structure based modeling approaches to index chemicals for their hH4R antagonism. PLoS One. 2014;9:e109340.

57. Feng Z, Hou T, Li Y. Docking and MD study of histamine H4R based on the crystal structure of H1R. J Mol Graph Model. 2013;39:1-12.

58. Farrens DL, Altenbach C, Yang K, et al. Requirement of rigid-body motion of transmembrane helices for light activation of rhodopsin. Science. 1996;274,768-770.

59. Łażewska D, Więcek M, Ner J, et al. Aryl-1,3,5-triazine derivatives as histamine H4 receptor ligands. Eur J Med Chem. 2014;83:534-546.

60. Engelhardt H, Schultes S, de Graaf C, et al. Bispyrimidines as potent histamine H(4) receptor ligands: delineation of structure-activity relationships and detailed $\mathrm{H}(4)$ receptor binding mode. $\mathrm{J}$ Med Chem. 2013;56:4264-4276.

61. Beuming T, Sherman W. Current assessment of docking into GPCR crystal structures and homology models: successes, challenges, and guidelines. J Chem Inf Model. 2012;52:3263-3277. 
*This study reports the comparative analysis of screening performances obtained by multipletemplate homology models and X-ray structure of the human histamine $\mathrm{H} 1$ receptor 
Table 1. Key interaction points for histamine $\mathrm{H} 1$ and $\mathrm{H} 2$ receptor ligands identified by modeling (1) and confirmed experimentally (2). Residues found to be not involved in binding are also indicated $(0)$.

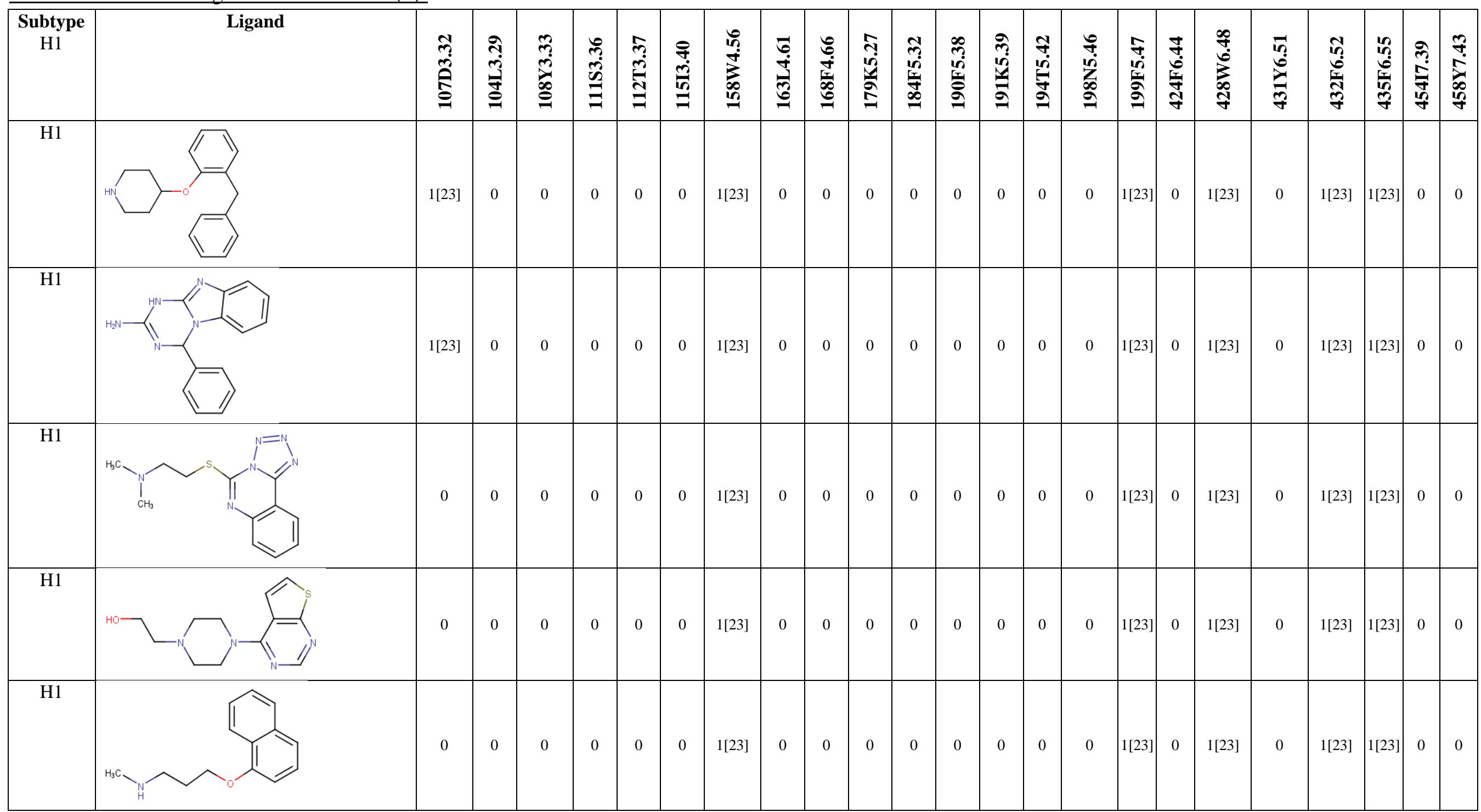




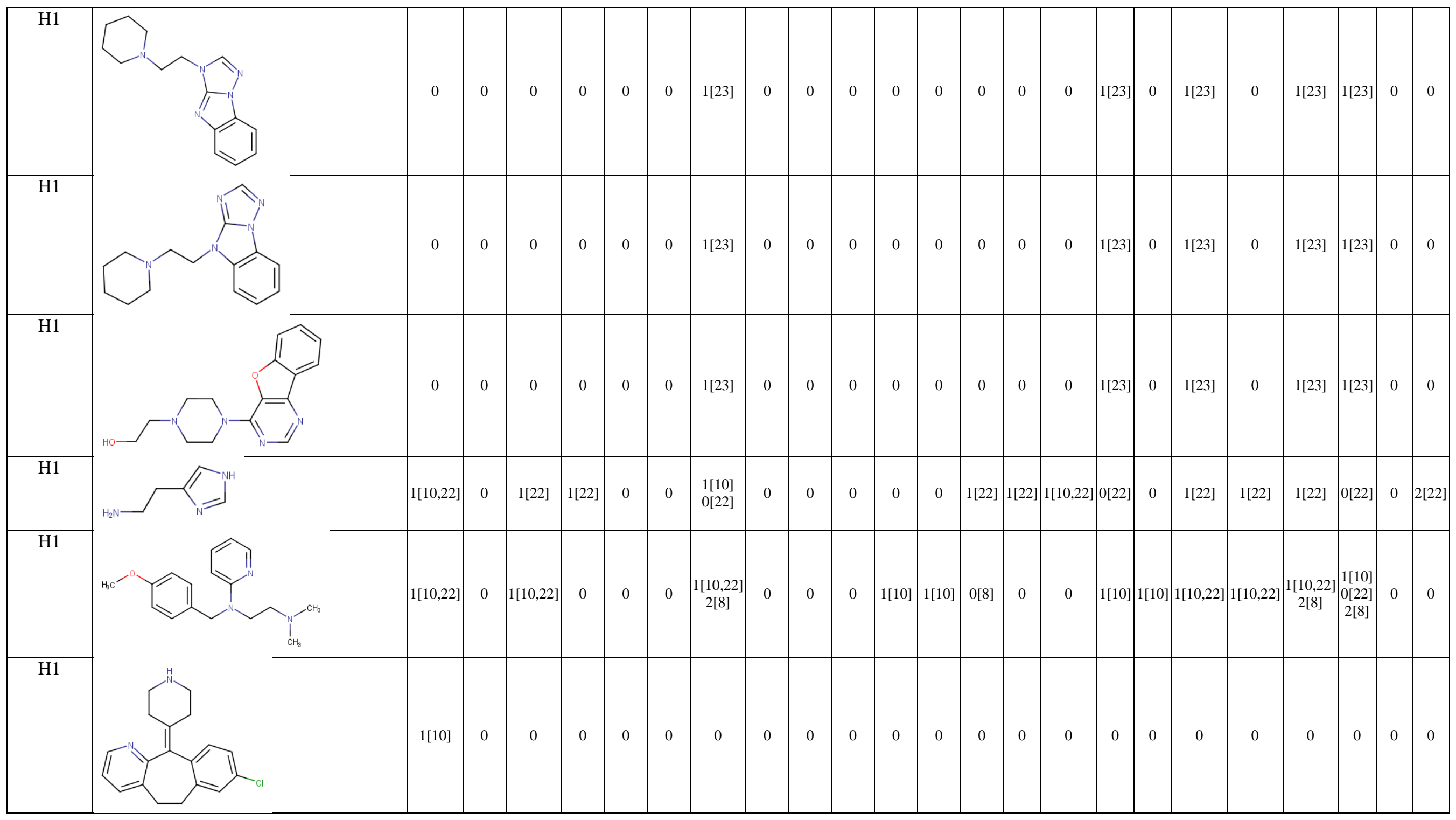




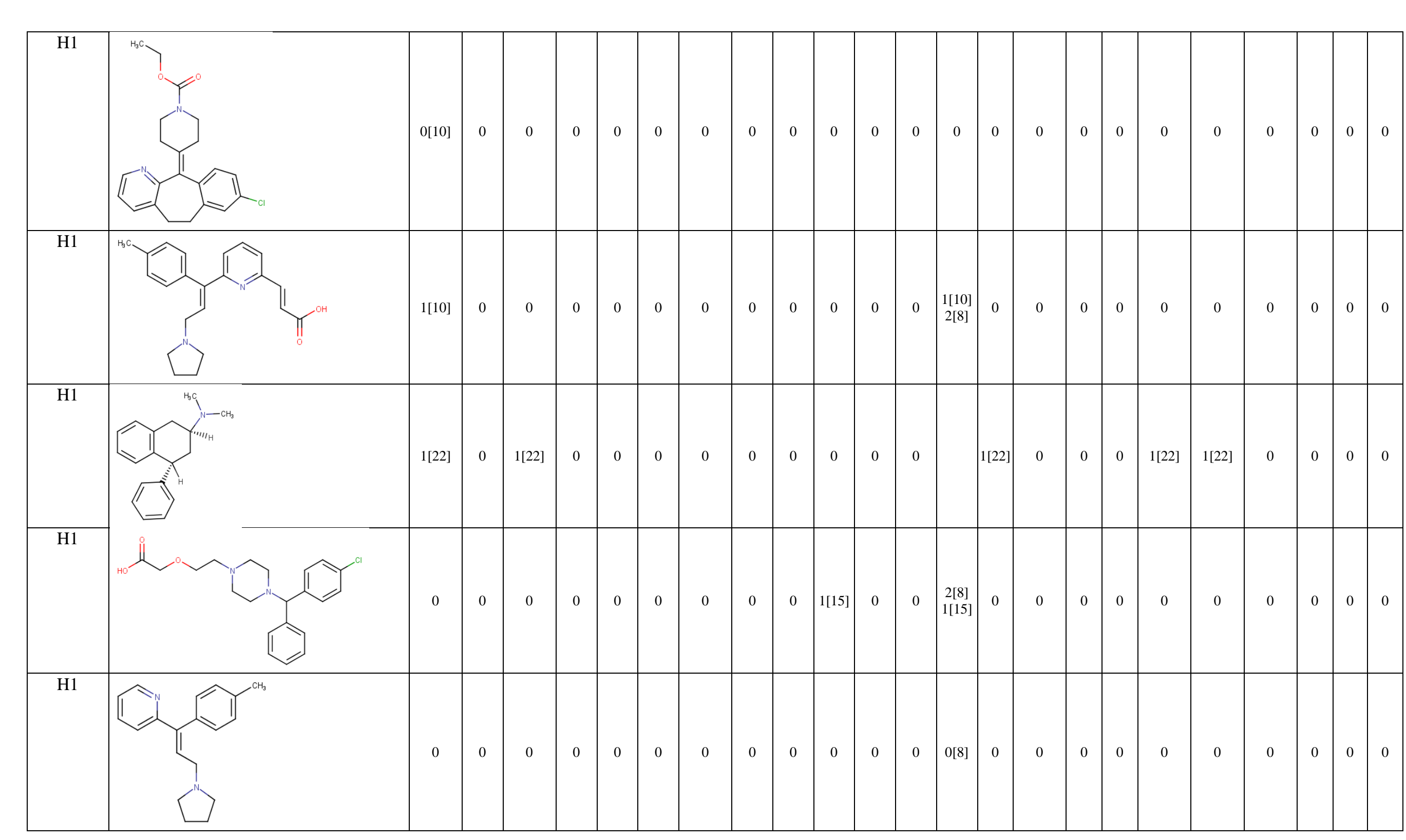




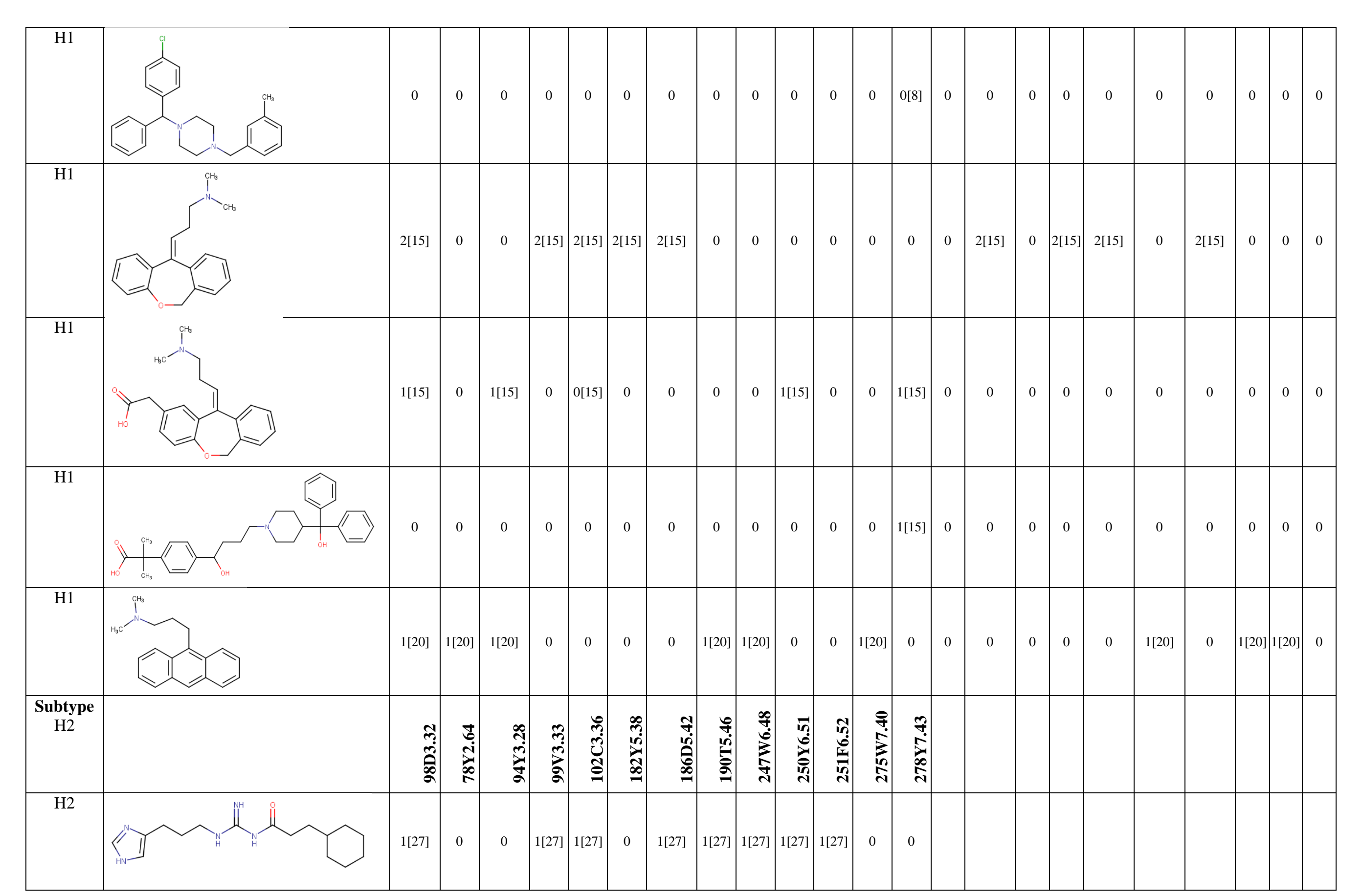




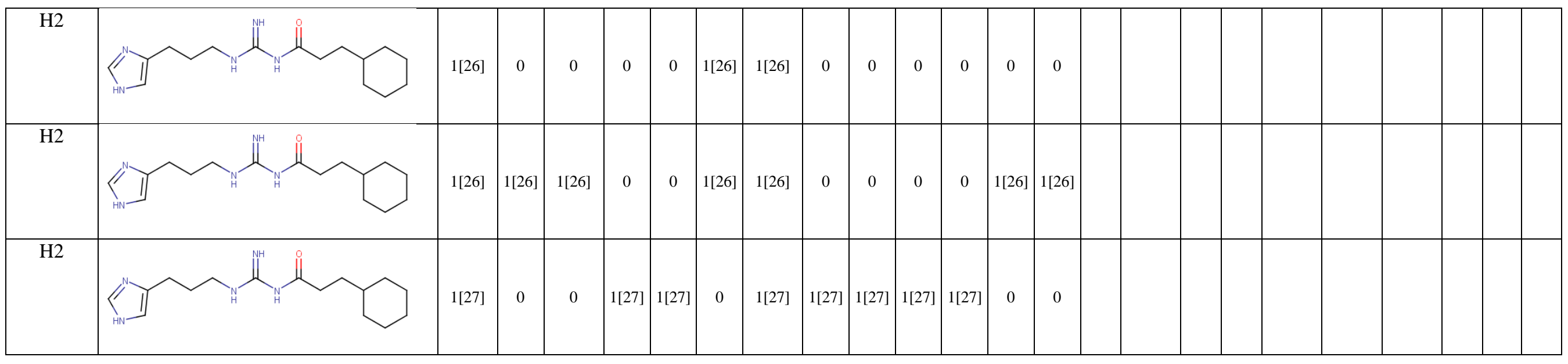


Table2. Key interaction points for histamine H3 receptor ligands identified by modeling (1) and confirmed experimentally (2). Residues found to be not involved in binding are also indicated (0).

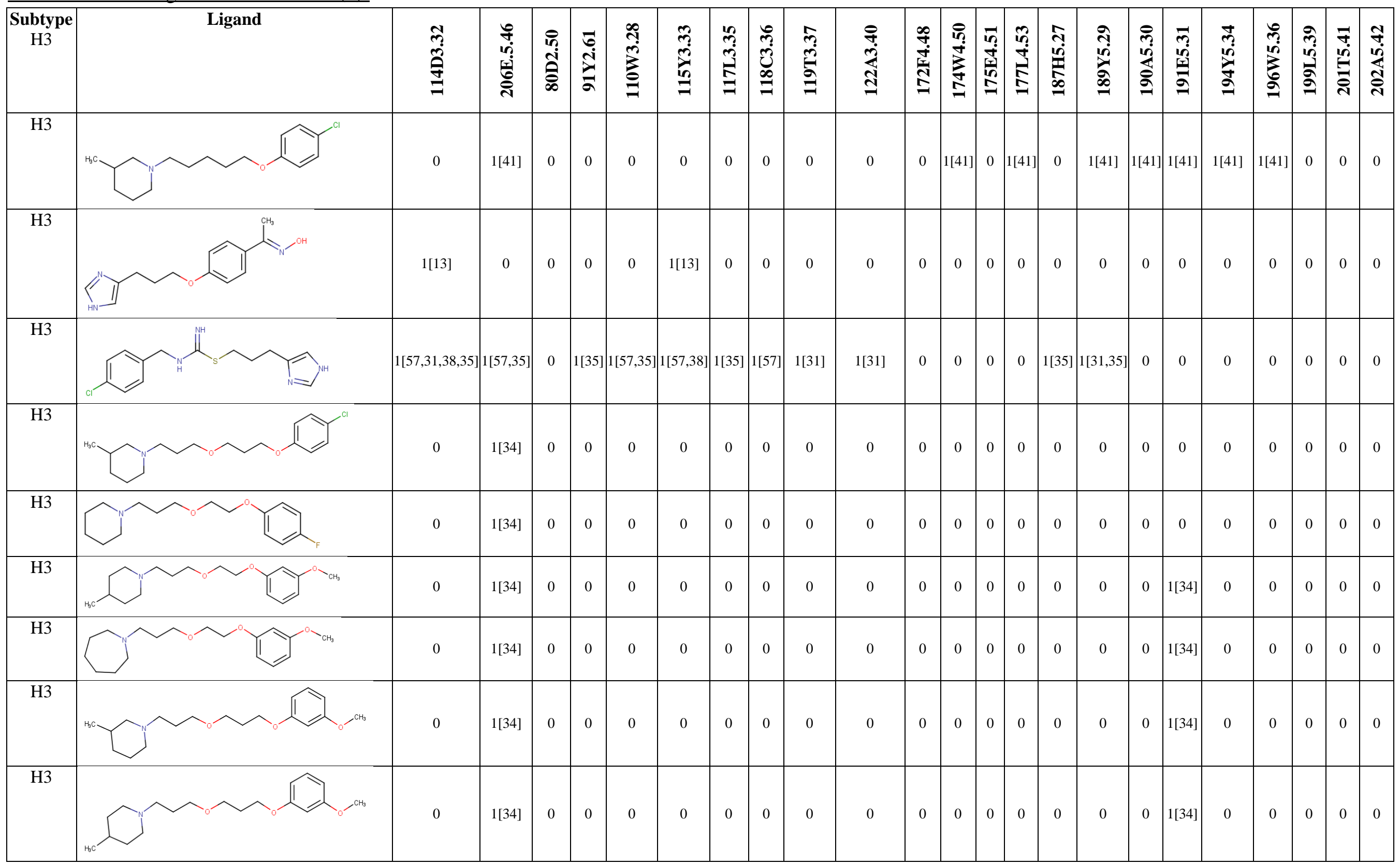




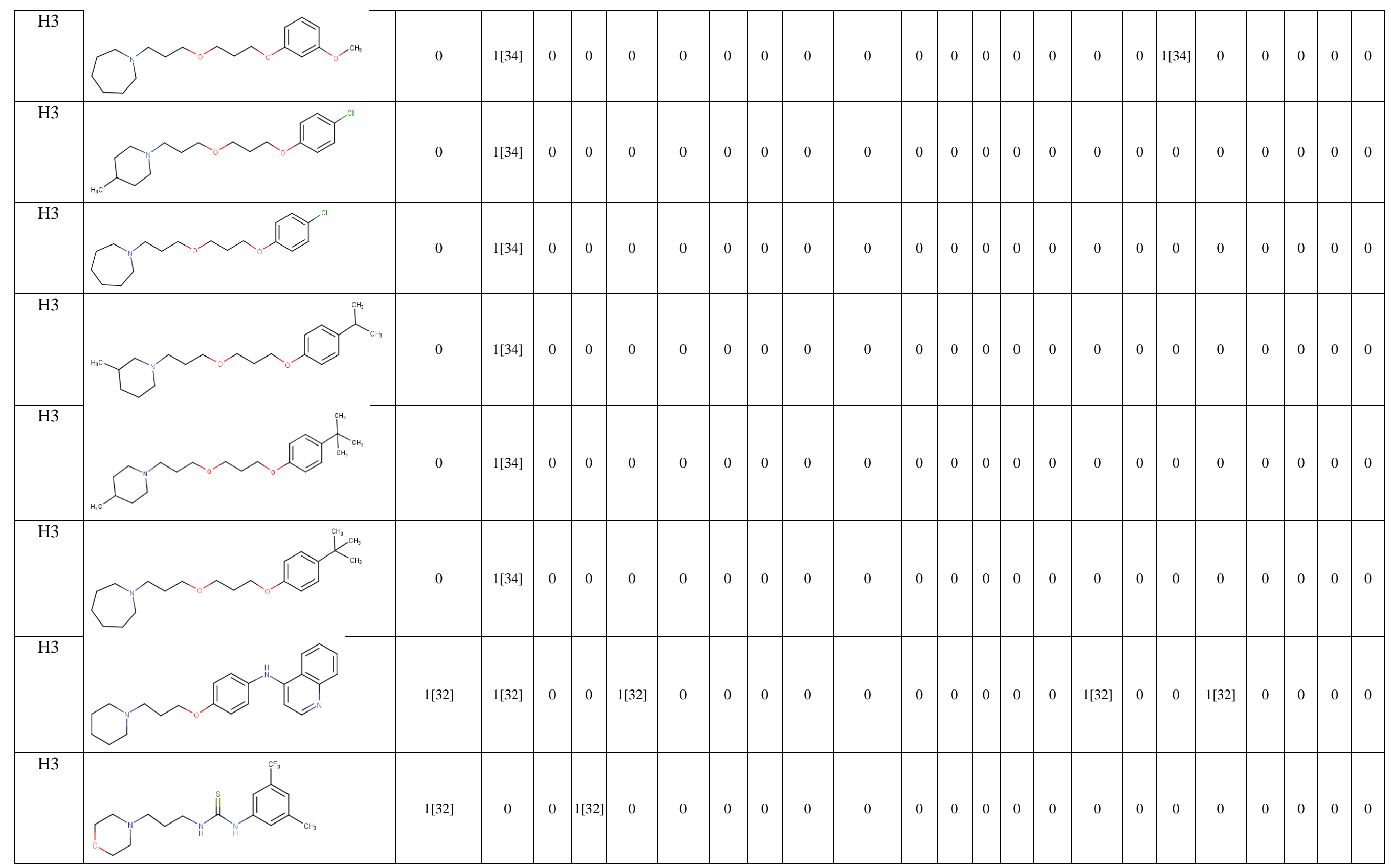




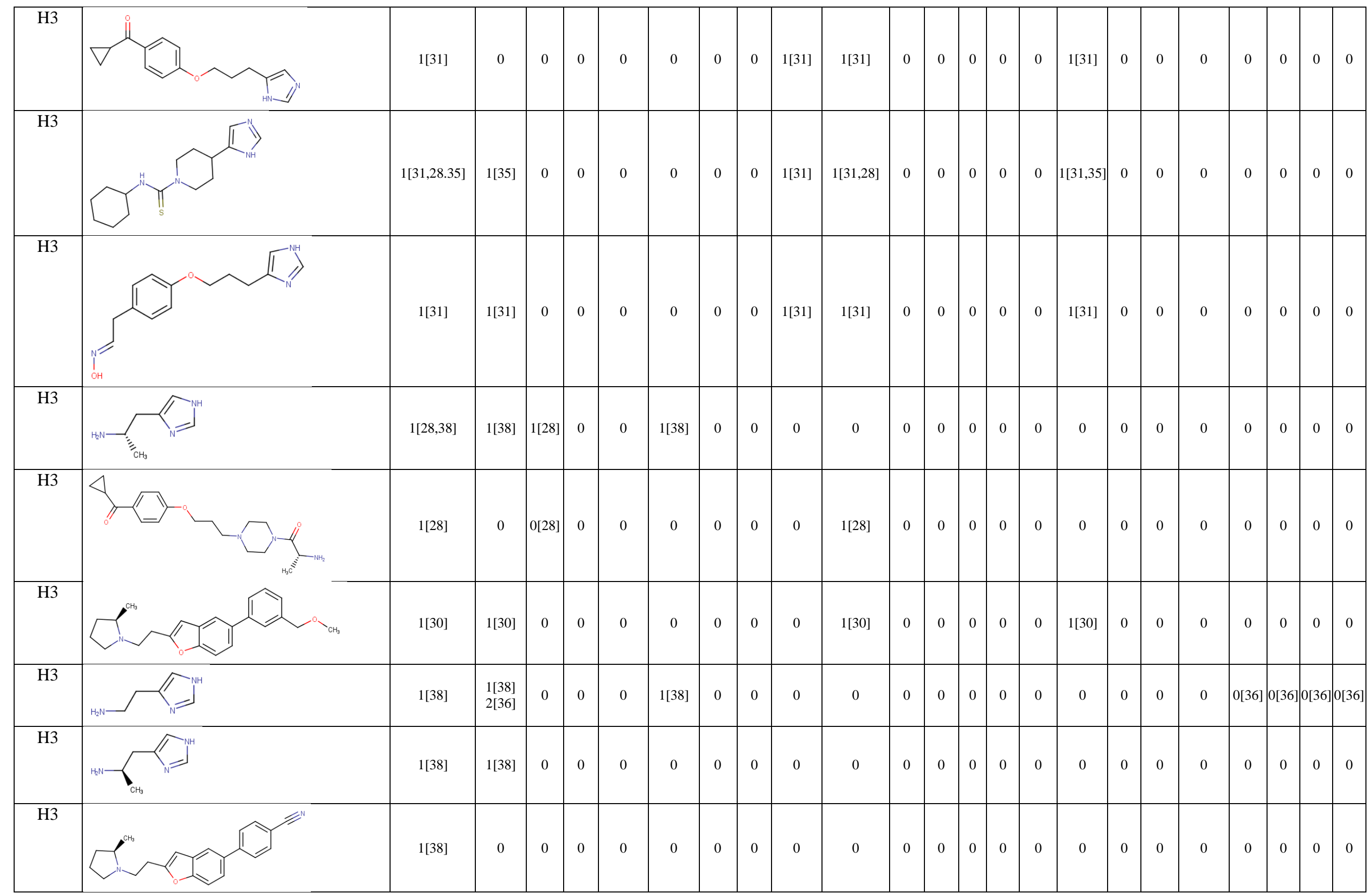




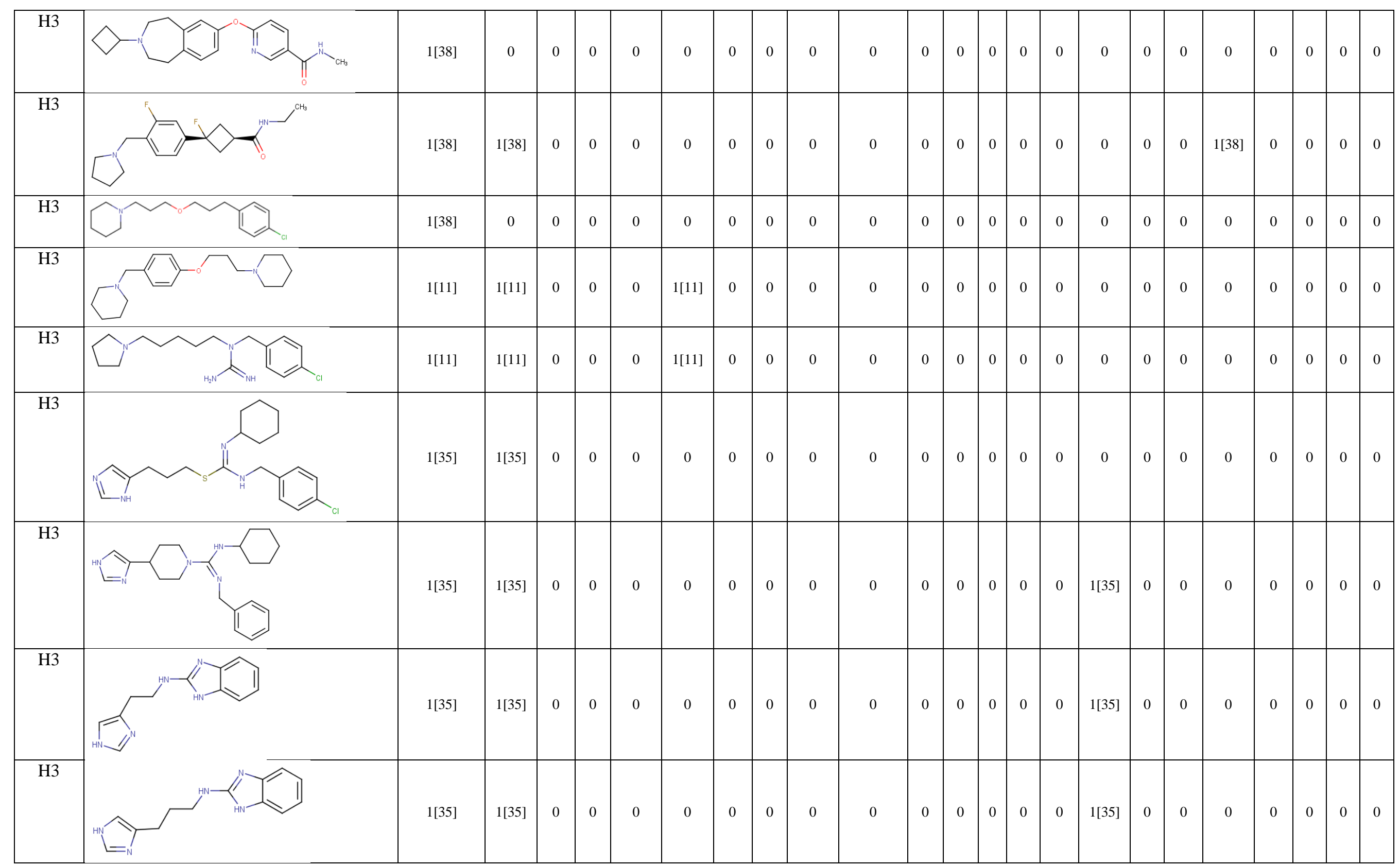




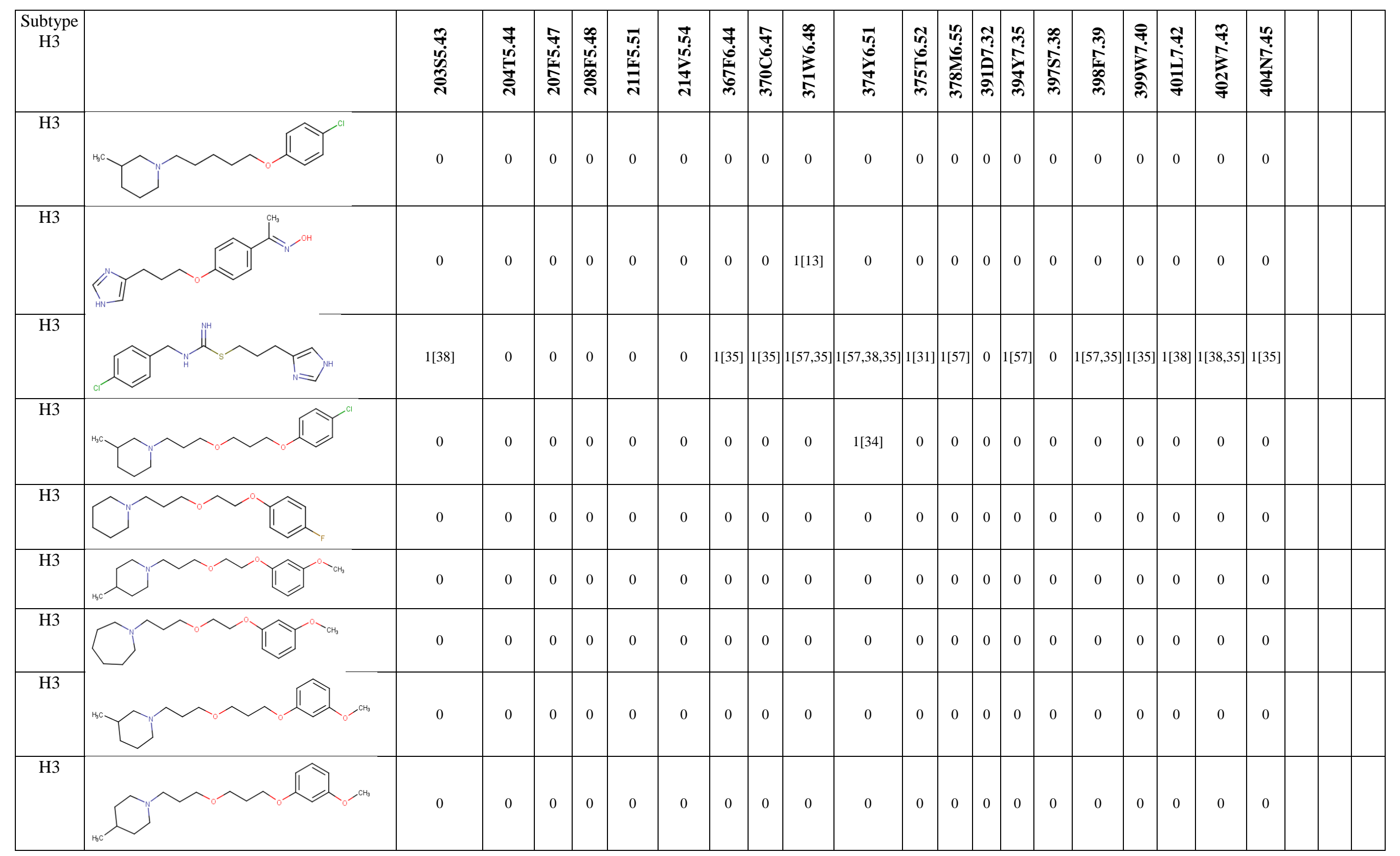




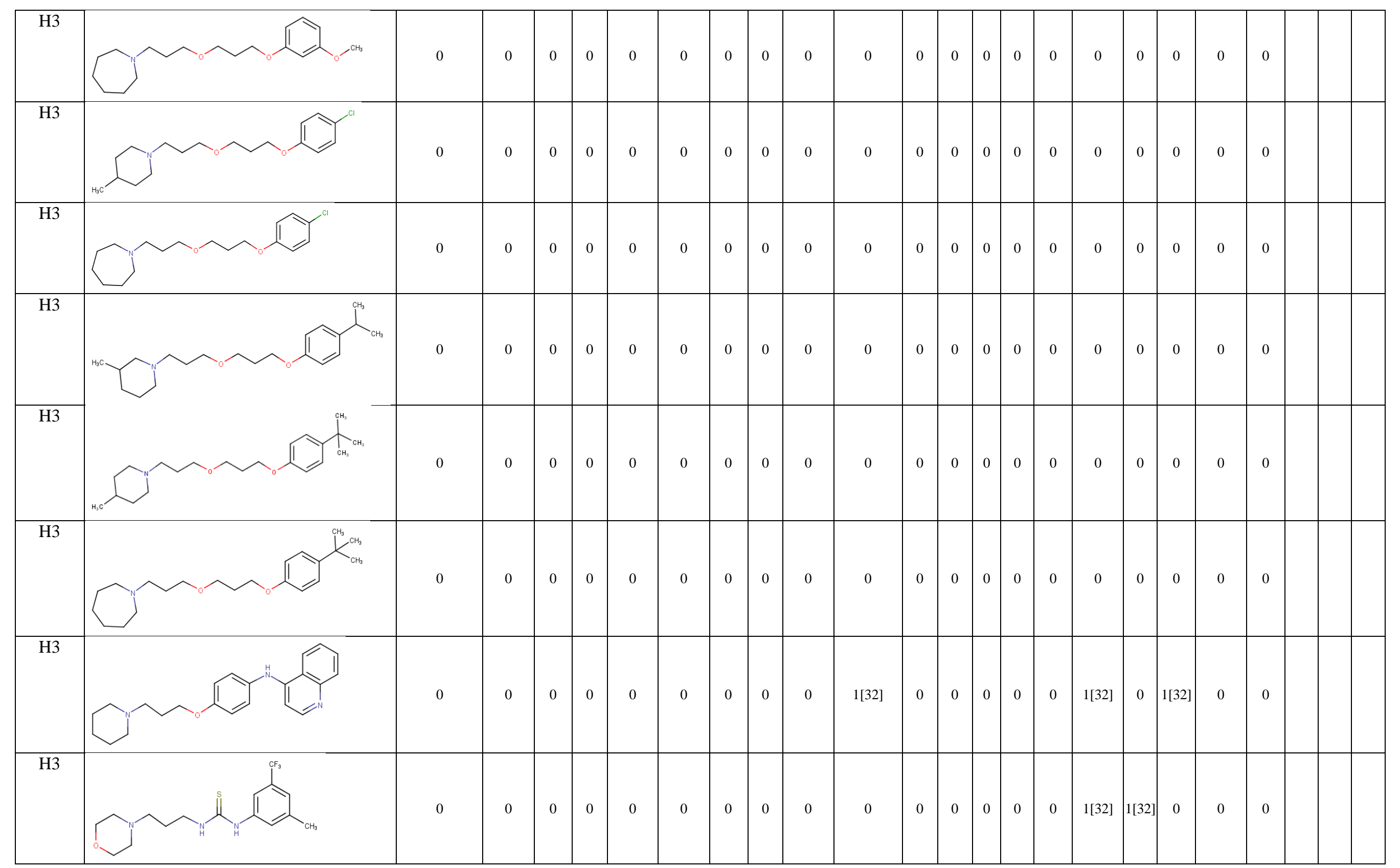




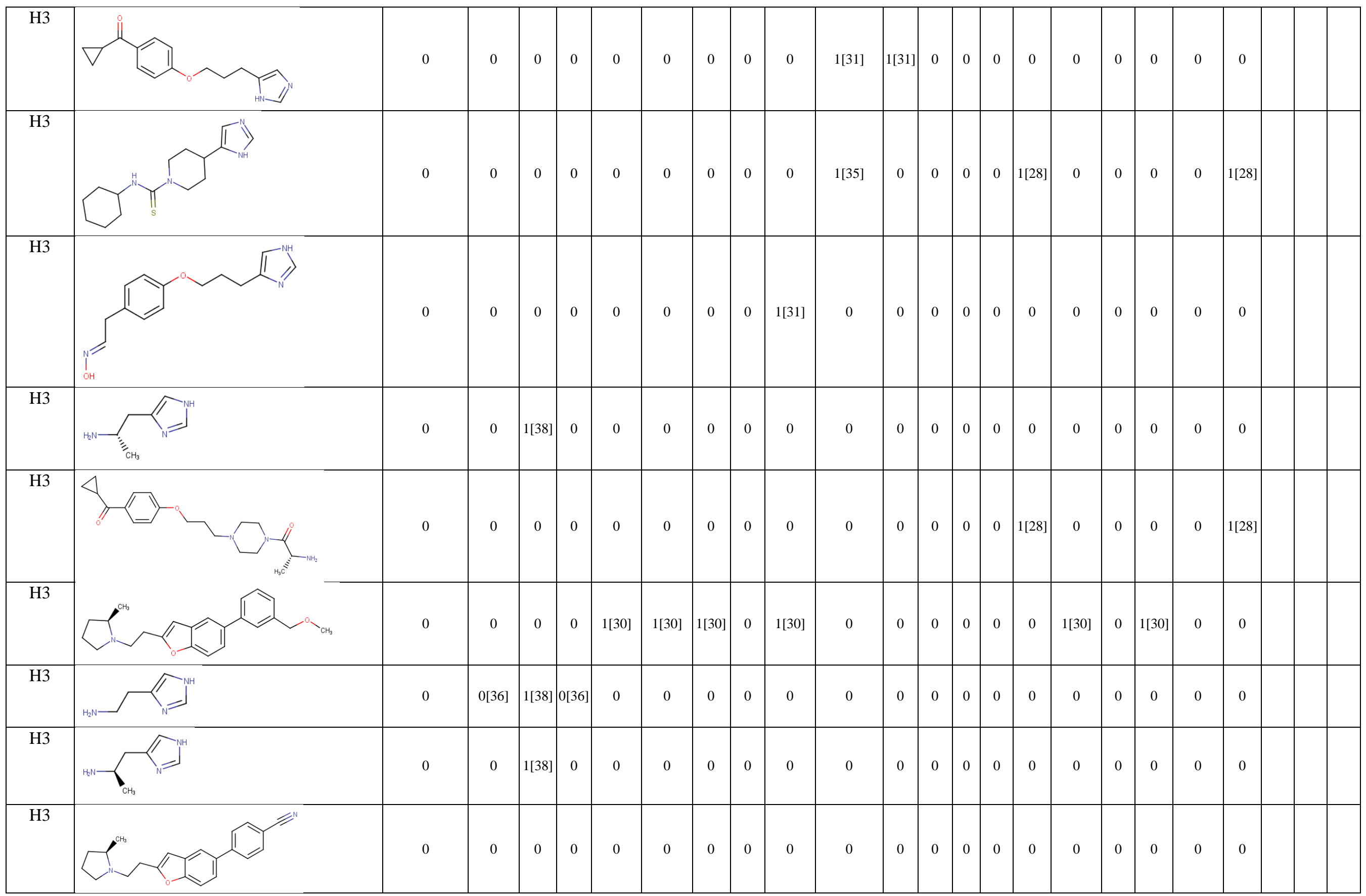




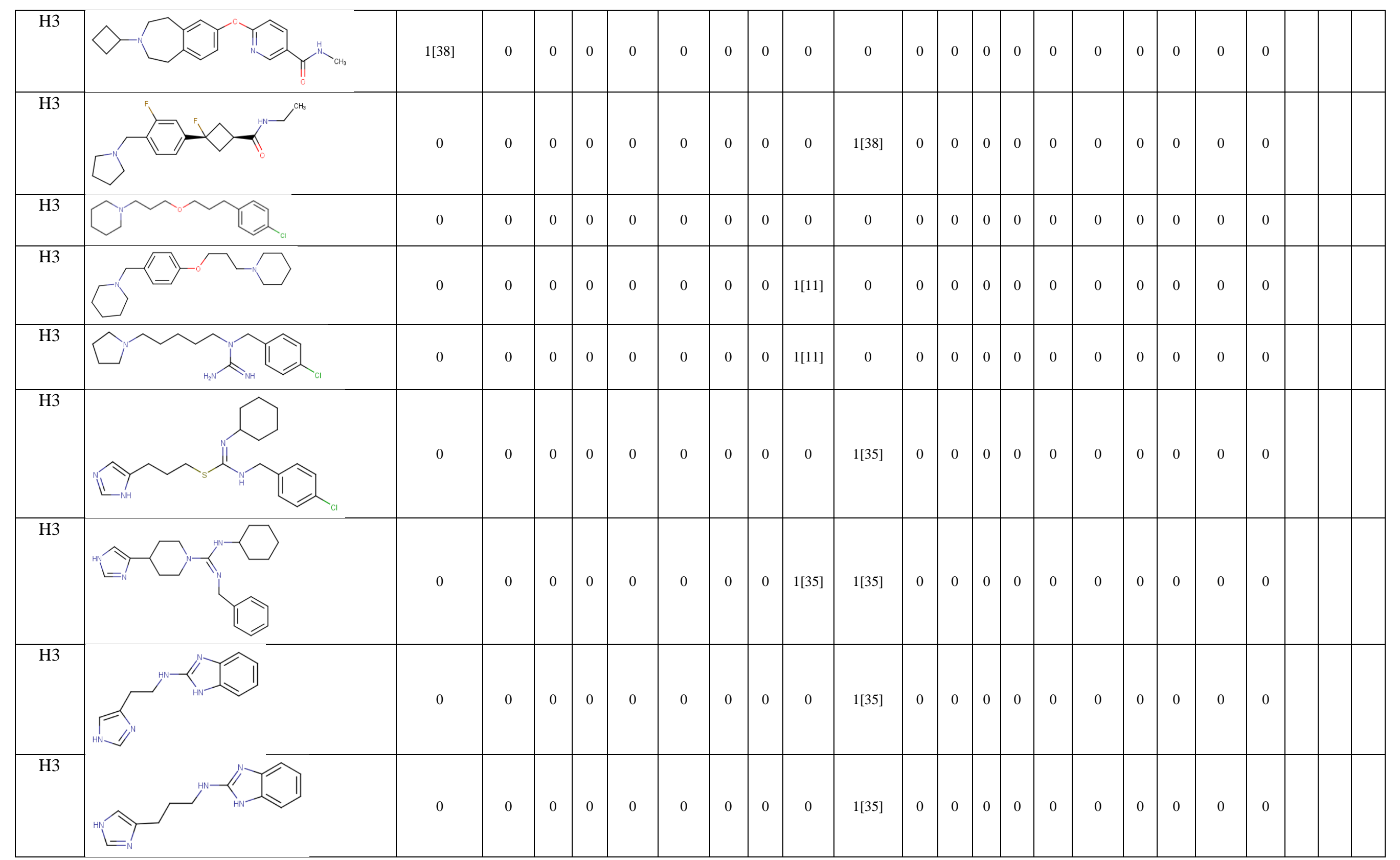


Table3. Key interaction points for histamine H4 receptor ligands identified by modeling (1) and confirmed experimentally (2). Residues found to be not involved in binding are also indicated (0).

\begin{tabular}{|c|c|c|c|c|c|c|c|c|c|c|c|c|c|c|c|c|c|c|c|c|c|c|c|c|}
\hline $\begin{array}{c}\text { Subtype } \\
\text { H4 }\end{array}$ & 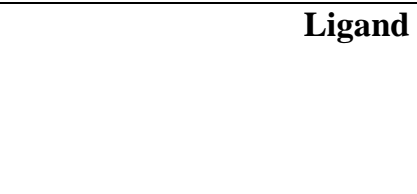 & थैं & 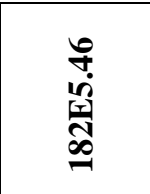 & $\sum_{\substack{n \\
i}}^{n}$ & $\begin{array}{l}\infty \\
i n \\
\\
\hat{\sigma}\end{array}$ & $\begin{array}{l}\bar{\sigma} \\
\text { ì } \\
\text { ָे }\end{array}$ & חั & નุ' & $\stackrel{m}{\ddot{z}}$ & 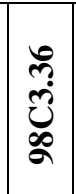 & 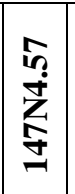 & 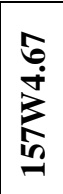 & 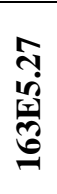 & 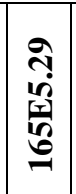 & 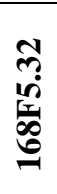 & 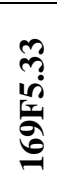 & $\begin{array}{c}\text { ले } \\
\text { in } \\
\text { ñ }\end{array}$ & 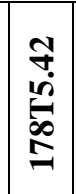 & 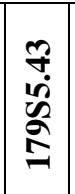 & 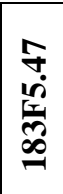 & 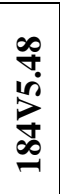 & 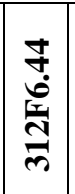 & $\sum_{\frac{m}{\infty}}^{\infty}$ & 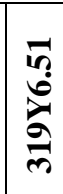 \\
\hline $\mathrm{H} 4$ & " & $1[52]$ & 0 & 0 & 0 & 0 & 0 & 0 & 0 & 0 & 0 & 0 & 0 & 0 & 0 & 0 & 0 & 0 & 0 & 0 & 0 & 0 & 0 & 0 \\
\hline $\mathrm{H} 4$ & & $1[52]$ & 0 & 0 & 0 & 0 & 0 & 0 & 0 & 0 & 0 & 0 & 0 & 0 & 0 & 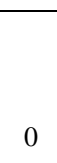 & 0 & 0 & 0 & 0 & 0 & 0 & 0 & 0 \\
\hline $\mathrm{H} 4$ & & $1[52]$ & 0 & 0 & 0 & 0 & 0 & 0 & 0 & 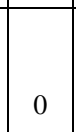 & 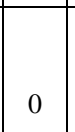 & 0 & 0 & 0 & 0 & 0 & 0 & 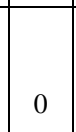 & 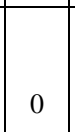 & 0 & 0 & 0 & 0 & 0 \\
\hline $\mathrm{H} 4$ & & $1[52]$ & 0 & 0 & 0 & 0 & 0 & 0 & 0 & 0 & 0 & 0 & 0 & 0 & 0 & 0 & 0 & 0 & 0 & 0 & 0 & 0 & 0 & 0 \\
\hline $\mathrm{H} 4$ & & $1[52]$ & 0 & 0 & 0 & 0 & 0 & 0 & 0 & 0 & 0 & 0 & 0 & 0 & 0 & 0 & 0 & 0 & 0 & 0 & 0 & 0 & 0 & 0 \\
\hline $\mathrm{H} 4$ & & $\begin{array}{c}1[43,42,46,57,47 \\
]\end{array}$ & $\begin{array}{c}1[43,42,47] \\
0[46]\end{array}$ & $1[42]$ & 0 & 0 & 0 & 0 & $\begin{array}{c}1[57 \\
]\end{array}$ & 0 & $0[43$ & 0 & 0 & $0[43$ & 0 & 0 & $\begin{array}{c}2[60,47 \\
]\end{array}$ & 0 & 0 & 0 & 0 & $\begin{array}{c}1[42 \\
]\end{array}$ & $1[42]$ & $\begin{array}{c}1[42 \\
]\end{array}$ \\
\hline
\end{tabular}




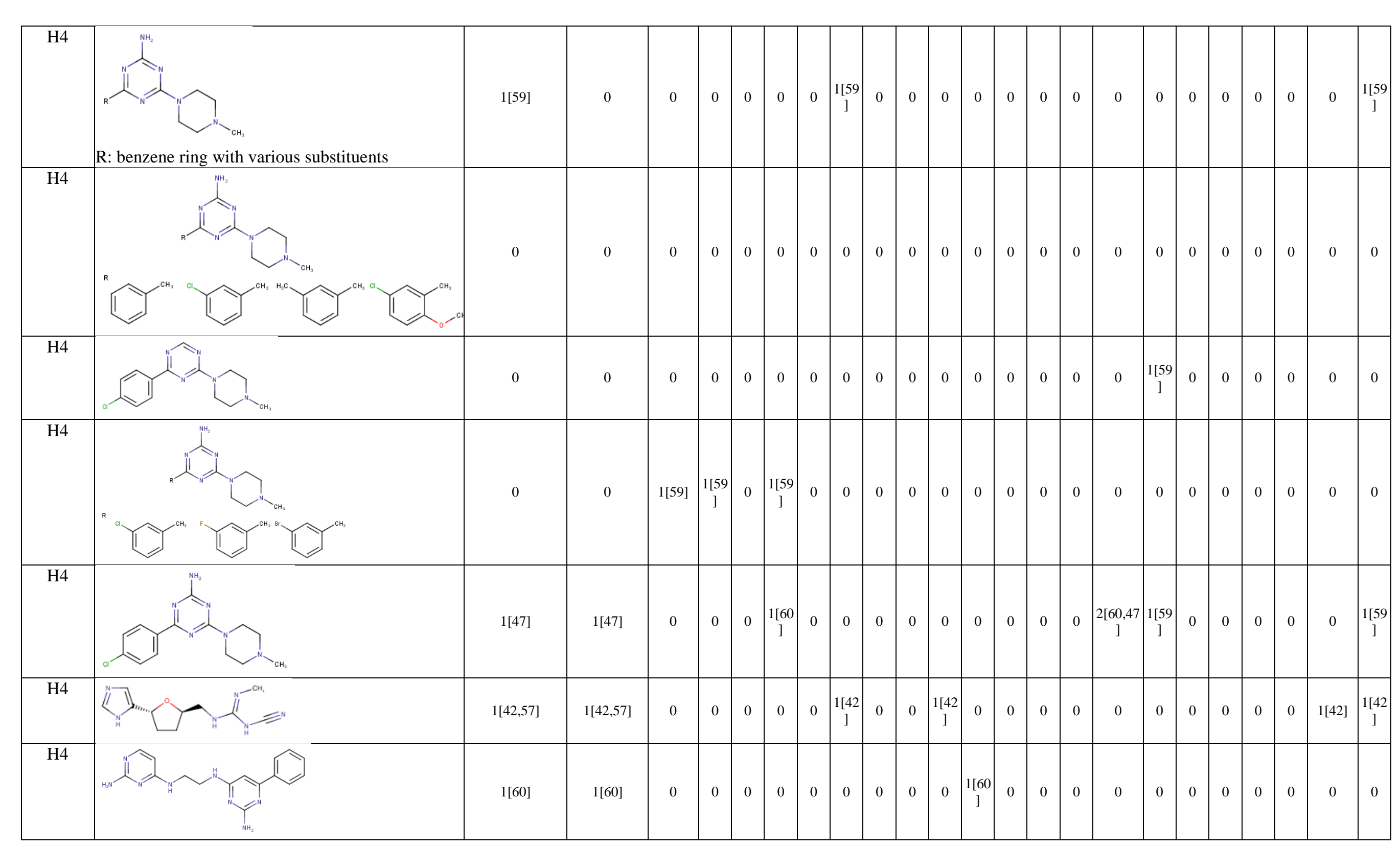




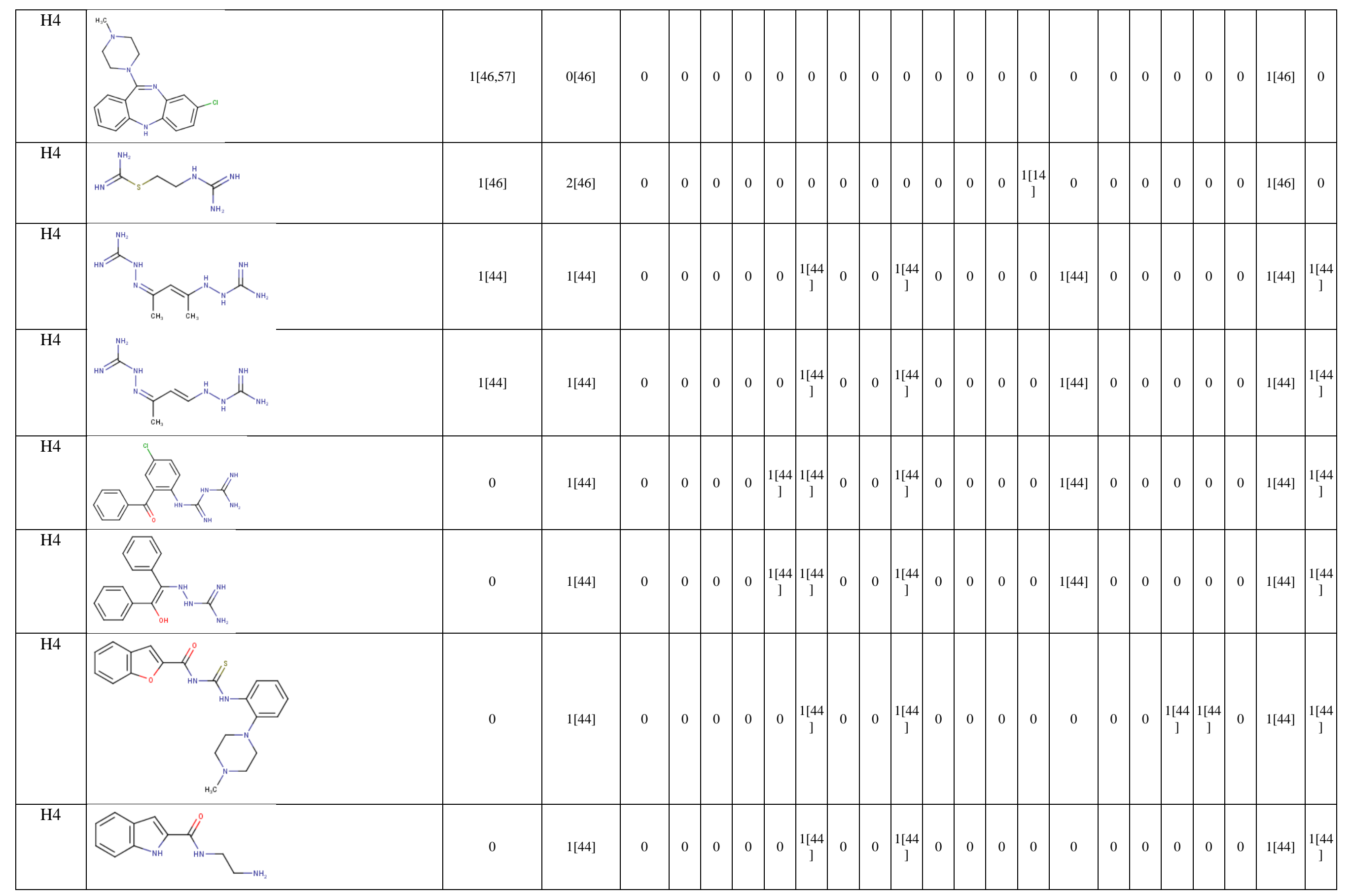




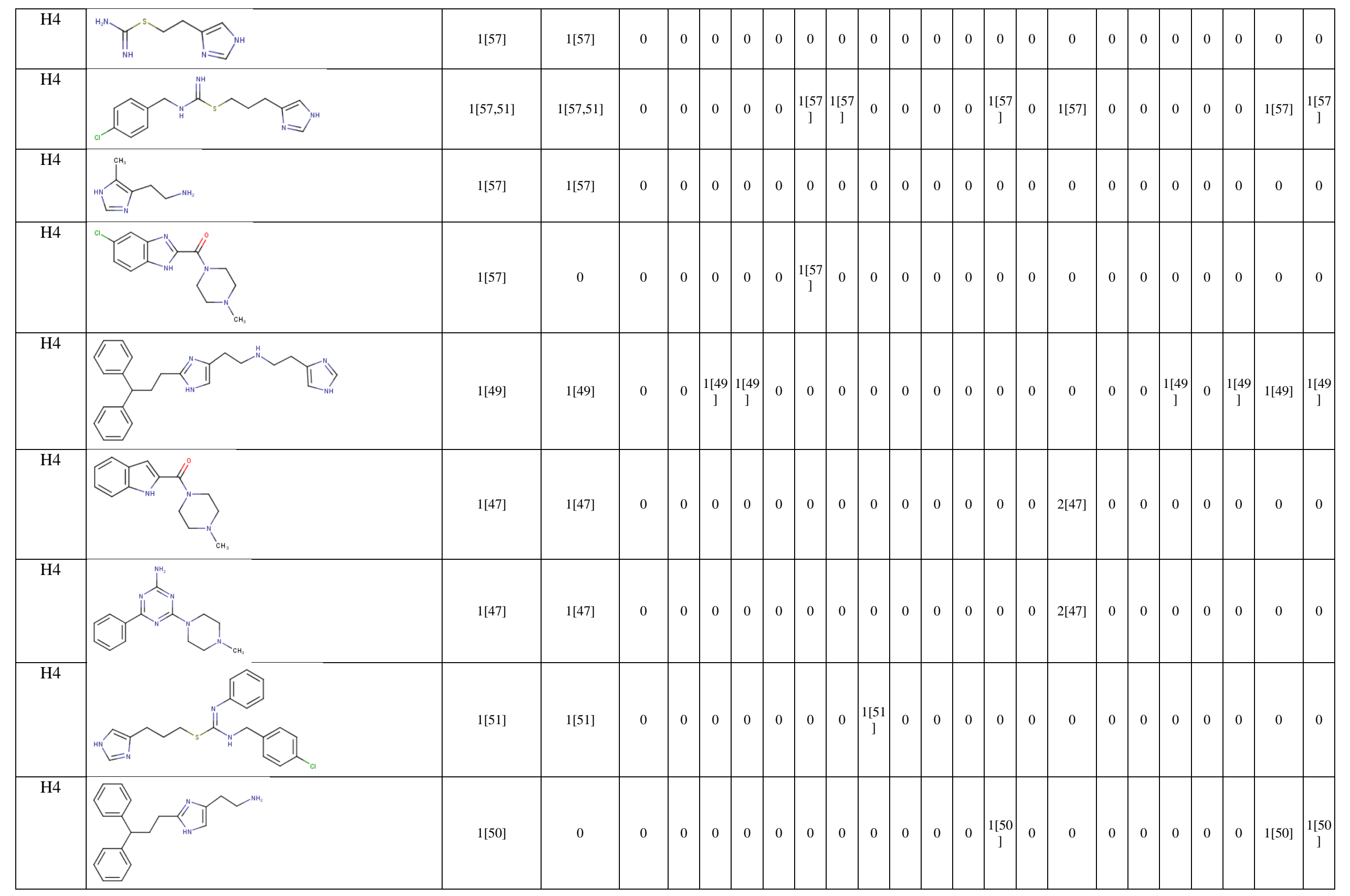




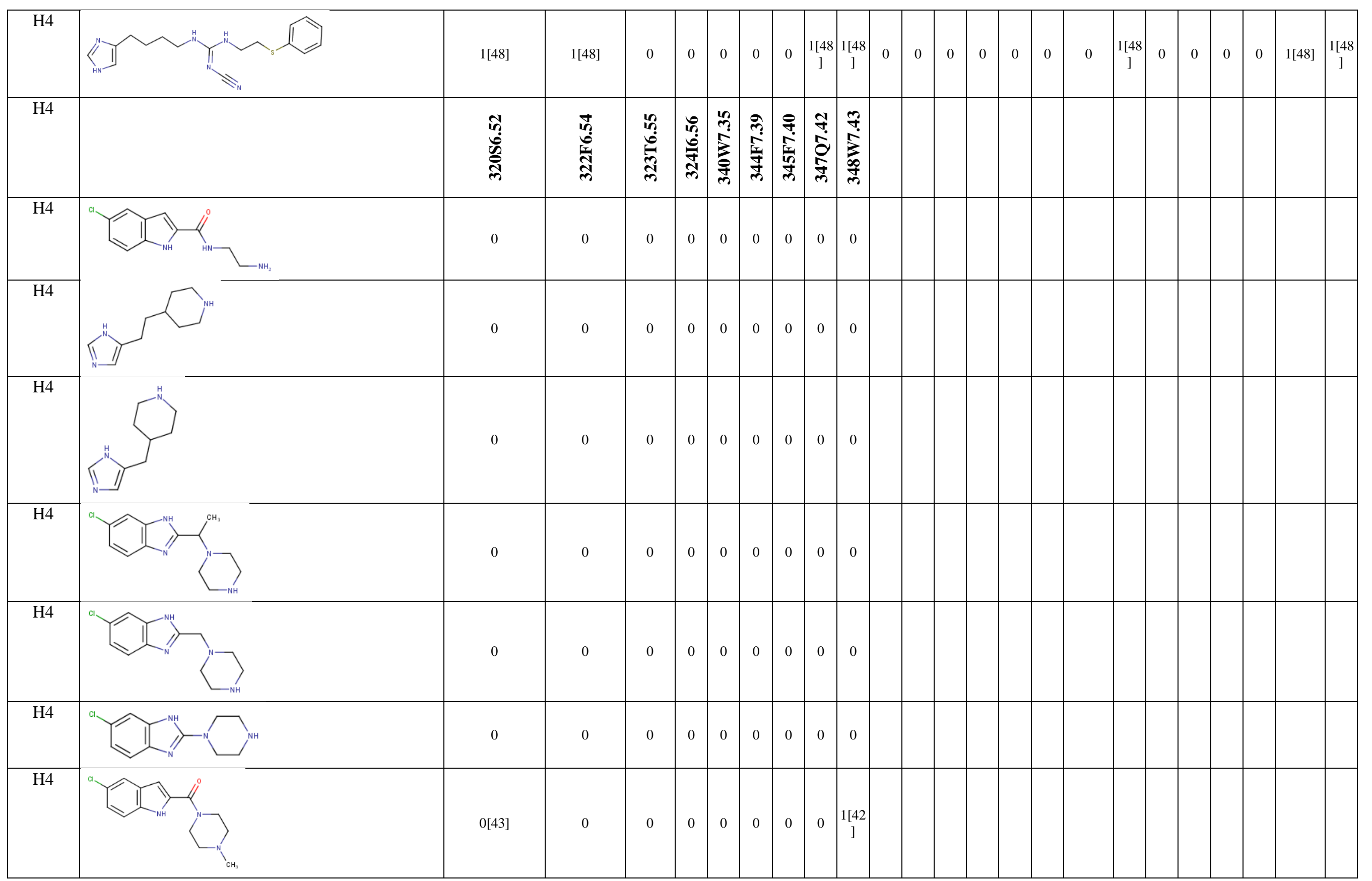




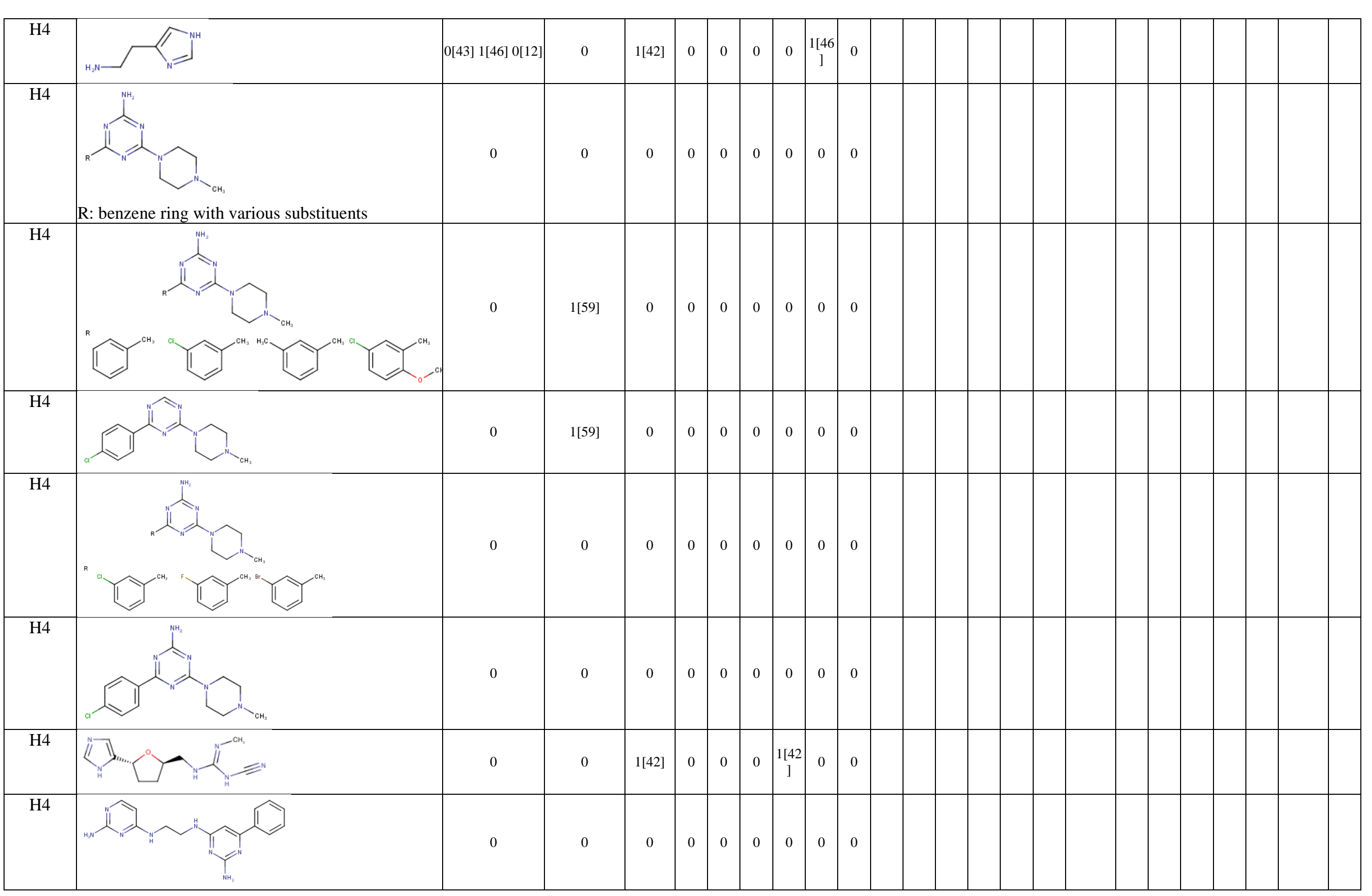




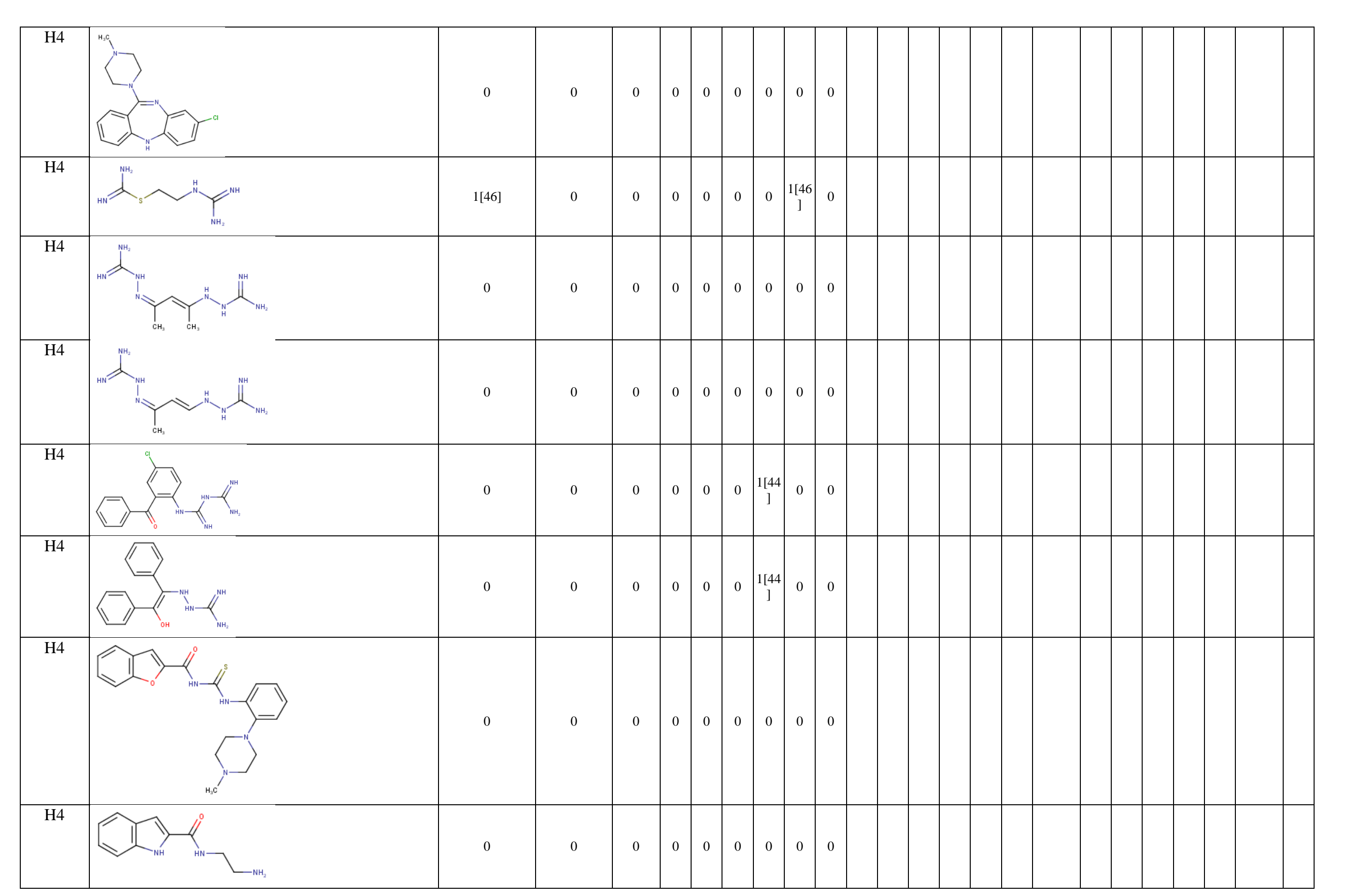




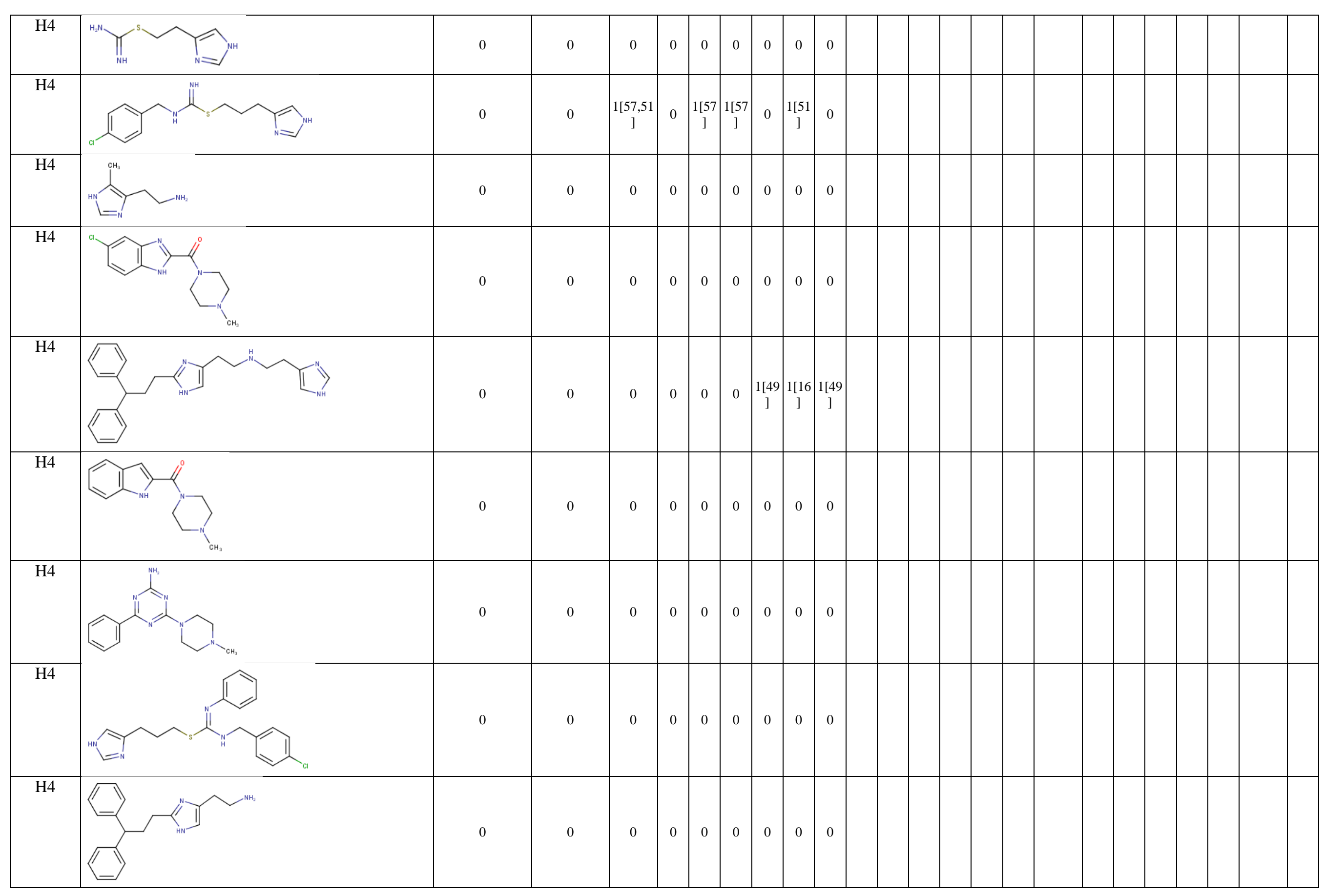




\begin{tabular}{|l|l|l|l|l|l|l|l|l|l|l|l|l|l|l|l|l|l|l|l|l|l|l|l|}
\hline $\mathrm{H} 4$ & 0 & 0 & 0 & 0 & 0 & $1[48$ & 0 & 0 & $1[16$ & & & & & & & & & & & & & & \\
\hline
\end{tabular}


Table4. Retrospective and prospective structure-based virtual screening studies on histamine receptors collected from the literature.

\begin{tabular}{|c|c|c|c|c|c|c|c|c|c|c|}
\hline \multirow[b]{2}{*}{ Subtype } & \multirow[b]{2}{*}{ Template } & \multirow[b]{2}{*}{ Seq identity } & \multicolumn{2}{|c|}{ Software } & \multicolumn{5}{|c|}{ Screening } & \multirow[b]{2}{*}{ Reference } \\
\hline & & & $\begin{array}{c}\text { Protein } \\
\text { modelling }\end{array}$ & Docking & Database & $\mathbf{A}$ & Hit rate & $\mathrm{EF}(\%)$ & Best Compound & \\
\hline $\mathrm{H} 4$ & $\begin{array}{l}\text { bovine } \\
\text { rhodopsin }\end{array}$ & $21 \%$ & Modeller & FlexX-Pharm & $\begin{array}{c}\text { Otava/Enamine } \\
\text { decoys + literature } \\
\text { actives }\end{array}$ & $\begin{array}{c}999,1483 \text { and } \\
3002 \text { decoys }+ \\
14 \text { actives }\end{array}$ & - & $\begin{array}{l}92.1 \text { (at } \\
\text { top0.5\%) }\end{array}$ & - & [42] \\
\hline \multirow[t]{2}{*}{$\mathrm{H} 1$} & \multirow[t]{2}{*}{$\mathrm{H} 1 \mathrm{R}$} & \multirow[t]{2}{*}{$100 \%$} & \multirow[t]{2}{*}{ - } & PLANTS + IFP & $\begin{array}{l}\text { ZINC, fragment- } \\
\text { like, filtered for } \\
\text { basic moiety }\end{array}$ & 95,147 & $73 \%$ & - & $\mathrm{pKi}=8.68$ & \multirow[t]{2}{*}{ [23] } \\
\hline & & & & & $\begin{array}{l}543 \text { ChEMBL and } \\
59 \text { CNS drug } \\
\text { active sets, } 7088 \\
\text { Bioinfo db decoys }\end{array}$ & - & - & $\begin{array}{c}39.3 \\
\text { (ChEMBL), } \\
57.6 \text { (CNS } \\
\text { drugs) } \\
\end{array}$ & & \\
\hline $\mathrm{H} 4$ & $\begin{array}{l}\text { bovine } \\
\text { rhodopsin }\end{array}$ & $21 \%$ & Modeller & FlexX & ZINC + suppliers & $8.7 \mathrm{M}$ & $\begin{array}{c}4.6 \% \\
\text { (selection 1), } \\
7.2 \% \\
\text { (selection 2), } \\
4.3 \% \\
\text { (selection 3) }\end{array}$ & 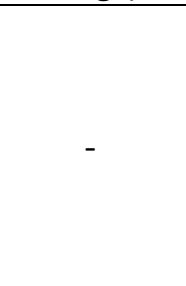 & $\mathrm{Ki}=85 \mathrm{nM}$ & [44] \\
\hline $\mathrm{H} 1$ & $\begin{array}{c}\text { bovine } \\
\text { rhodopsin } \\
\text { and beta2- } \\
\text { adrenergic } \\
\text { receptor }\end{array}$ & $\begin{array}{c}18 \% \\
\text { (b.rhod) / } \\
31 \% \\
\text { (beta2) }\end{array}$ & Modeller & Glide SP & $\begin{array}{c}\text { ZINC DUD decoys } \\
+ \text { Drugbank } \\
\text { actives }\end{array}$ & & 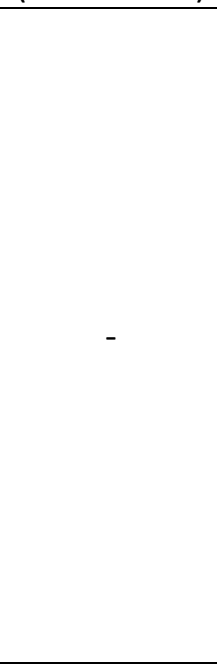 & $\begin{array}{c}\text { Tc50 }>0.5 \\
- \\
\text { enrichme } \\
n t \\
\text { indicator } \\
\text { calculated } \\
\text { from a } \\
\text { protein } \\
\text { ligand } \\
\text { interactio } \\
n \\
\text { fingerprin } \\
t \text { (PLIF) } \\
\text { and its }\end{array}$ & - & [21] \\
\hline
\end{tabular}




\begin{tabular}{|c|c|c|c|c|c|c|c|c|c|c|}
\hline & & & & & & & & $\begin{array}{l}\text { Tanimoto } \\
\text { coefficient }\end{array}$ & & \\
\hline $\mathrm{H} 1$ & H1 X-ray & $100 \%$ & - & PLANTS + IFP & $\begin{array}{l}\text { ZINC, fragment- } \\
\text { like, filter for basic } \\
\text { moiety }\end{array}$ & 108,790 & $\begin{array}{l}61 \%, 45 \%, \\
\text { and } 73 \%, \\
\text { were } \\
\text { obtained for } \\
\text { the IFP, } \\
\text { PLANTS, and } \\
\text { combined } \\
\text { approaches }\end{array}$ & - & $p K i=8.20$ & [25] \\
\hline \multirow[t]{2}{*}{ H3 } & \multirow{2}{*}{$\begin{array}{l}\text { bovine } \\
\text { rhodopsin }\end{array}$} & \multirow[t]{2}{*}{$21 \%$} & \multirow{2}{*}{$\begin{array}{l}\text { replacing } \\
\text { bovine } \\
\text { rhodopsin } \\
\text { side } \\
\text { chains by } \\
\text { H3R using } \\
\text { SCWRL3.0 }\end{array}$} & \multirow[t]{2}{*}{ GOLD } & $\begin{array}{c}\text { in house actives + } \\
\text { WDI decoys }\end{array}$ & $\begin{array}{c}418 \text { actives + } \\
473 \\
\text { random/focus } \\
\text { ed WDI } \\
\text { decoys }\end{array}$ & - & $\begin{array}{c}11.4 \% \\
\text { random } \\
\text { and } 23 \% \\
\text { focused } \\
\text { decoys in } \\
\text { the top } \\
80 \% \\
\end{array}$ & - & \multirow[t]{2}{*}{ [32] } \\
\hline & & & & & $\begin{array}{c}\text { WDI / MDB } \\
\text { filtered: Mw }<600, \\
\text { sec/tert amine } \\
\text { functionality }>0\end{array}$ & 13,524 & $100 \%$ & 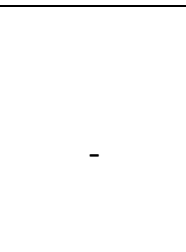 & $=$ & \\
\hline \multirow[b]{2}{*}{ H3 } & \multirow[b]{2}{*}{$\begin{array}{l}\text { bovine } \\
\text { rhodopsin }\end{array}$} & \multirow[b]{2}{*}{$21 \%$} & \multirow[b]{2}{*}{ Gmodel } & \multirow[b]{2}{*}{$\begin{array}{c}\text { Glide HTVS + } \\
\text { SP }\end{array}$} & in-house, lead-like & 400,000 & - & $\begin{array}{c}15 \text { (at top } \\
1 \% \text { ) }\end{array}$ & - & \multirow[b]{2}{*}{ [31] } \\
\hline & & & & & $\begin{array}{l}\text { GPCR SARfari } \\
\text { monoamine } \\
\text { actives }\end{array}$ & 700 & - & $\begin{array}{l}\sim 4.5 \text { (at } \\
\text { top } 10 \% \text { ) }\end{array}$ & - & \\
\hline H3 & $\begin{array}{l}\text { bovine } \\
\text { rhodopsin }\end{array}$ & $21 \%$ & Modeller & $\begin{array}{l}\text { Manual } \\
\text { docking and } \\
\text { MD } \\
\text { refinement }\end{array}$ & $\begin{array}{c}\text { training set: } \\
\text { literature } \mathrm{H3} \\
\text { antagonists (Ki: } 80 \\
\text { pM - } 10 \mathrm{uM} \text { ), test } \\
\text { set: in-house H3 } \\
\text { antagonists (Ki: } 26 \\
\text { pM - } 10 \mathrm{uM} \text { ) }\end{array}$ & $\begin{array}{c}100 \\
\text { (literature), } \\
1000 \text { (in- } \\
\text { house) }\end{array}$ & - & $\begin{array}{c}70 \% \\
\text { accuracy } \\
\text { in } \\
\text { discrimina } \\
\text { tion of } \\
\text { affinity } \\
\text { classes } \\
\end{array}$ & - & [29] \\
\hline $\mathrm{H} 4$ & $\mathrm{H} 1 \mathrm{R}$ & $25 \%$ & $\begin{array}{l}\text { replacing } \\
\text { H1R side }\end{array}$ & AutoDock 4.2 & $\begin{array}{c}\text { actives from } \\
\text { ChEMBL, decoys }\end{array}$ & $\begin{array}{l}56 \text { (actives), } \\
137 \text { (decoys) }\end{array}$ & - & $14.6-16.4$ & - & [56] \\
\hline
\end{tabular}




\begin{tabular}{|c|c|c|c|c|c|c|c|c|c|c|}
\hline & & & $\begin{array}{l}\text { chains by } \\
\text { H4R using } \\
\text { SCWRL }\end{array}$ & & from ZINC & & & & & \\
\hline $\mathrm{H} 4$ & $\begin{array}{l}\text { H1 3RZE + } \\
\text { beta2 for } \\
\text { TM4 kink }\end{array}$ & $\begin{array}{c}25 \%(\mathrm{H} 1 \mathrm{R}) \\
/ 27 \% \\
\text { (beta2) } \\
\end{array}$ & Modeller & Glide SP & GDD & $\begin{array}{c}30 \text { active and } \\
1170 \text { inactive } \\
\text { ligands }\end{array}$ & - & $\begin{array}{l}26.7 \text { (at } \\
\text { top1\%) }\end{array}$ & - & [54] \\
\hline \multirow[b]{2}{*}{ H3 } & \multirow[b]{2}{*}{ H1 3RZE } & \multirow[b]{2}{*}{$27 \%$} & \multirow[b]{2}{*}{ Modeller } & \multirow[b]{2}{*}{ FLAP } & $\begin{array}{c}\text { Actives: ChEMBL } \\
\text { with pKi> } 7.0+\text { in- } \\
\text { house } 60 \text { actives } \\
\text { ( } \geq 50 \% \text { radioligand } \\
\text { displacement } \\
\text { from H3R at } 10 \\
\mu \mathrm{M}) \text {, decoys: } 871 \\
\text { inactives }\end{array}$ & $\begin{array}{l}60 \text { (in-house } \\
\text { actives), } 871 \\
\text { (decoys) }\end{array}$ & - & $\begin{array}{l}26.6-61.3 \\
\text { (at top1\%) }\end{array}$ & - & \\
\hline & & & & & ZINC fragment-like & 156090 & 18 / 29 (62\%) & - & & [39] \\
\hline $\mathrm{H} 4$ & $\begin{array}{l}\text { H1 3RZE + } \\
\text { beta2 for } \\
\text { TM4 kink }\end{array}$ & $\begin{array}{c}25 \%(\mathrm{H} 1 \mathrm{R}) \\
/ 27 \% \\
\text { (beta2) }\end{array}$ & Modeller & Glide SP & $\begin{array}{l}\text { in-house } \\
\text { fragments }\end{array}$ & 12905 & $8 / 50(16 \%)$ & - & $\mathrm{Ki}=8.4 \mu \mathrm{M}$ & [53] \\
\hline
\end{tabular}


Table 5. Most suitable templates for histamine receptor homology models suggested by the PDB database. Templates and corresponding values were obtained by searching on the sequence of histamine receptors excluding ICL3 region.

\begin{tabular}{|c|c|c|c|c|c|c|c|c|c|c|c|c|c|c|c|c|c|c|}
\hline & \multicolumn{6}{|c|}{ 1. template } & \multicolumn{6}{|c|}{ 2. template } & \multicolumn{6}{|c|}{ 3. template } \\
\hline & Name & PDB & Length & Identity & Positive & Gap & Name & PDB & Length & Identity & Positive & Gap & Name & PDB & Length & Identity & Positive & Gap \\
\hline $\mathrm{H} 1$ & $\mathrm{H} 1$ & 3RZE & 202 & $96 \%$ & $96 \%$ & $0 \%$ & M2 & 4MQS & 291 & $34 \%$ & $48 \%$ & $15 \%$ & beta2 & 4GBR & 281 & $32 \%$ & $52 \%$ & $12 \%$ \\
\hline $\mathrm{H} 2$ & beta2 & 4GBR & 284 & $33 \%$ & $53 \%$ & $10 \%$ & beta1 & 2VT4 & 281 & $35 \%$ & $51 \%$ & $13 \%$ & $\mathrm{M} 2$ & 4MQS & 288 & $29 \%$ & $44 \%$ & $17 \%$ \\
\hline $\mathrm{H} 3$ & M2 & $4 \mathrm{MQS}$ & 278 & $30 \%$ & $51 \%$ & $16 \%$ & M1 & $5 \mathrm{CXV}$ & 160 & $41 \%$ & $63 \%$ & $1 \%$ & M3 & 4DAJ & 167 & $37 \%$ & $61 \%$ & $1 \%$ \\
\hline $\mathrm{H} 4$ & M3 & $4 \mathrm{U} 15$ & 161 & $36 \%$ & $59 \%$ & $4 \%$ & M1 & $5 \mathrm{CXV}$ & 175 & $34 \%$ & $54 \%$ & $5 \%$ & M2 & 4MQS & 177 & $34 \%$ & $56 \%$ & $7 \%$ \\
\hline
\end{tabular}


